Research Article

\title{
Influences of Urban Viaduct Pier Caps on Uneven Settlement of Roadbed
}

\author{
Bin Hu (D), Xiaoqing Li, and Lifei Zheng (iD \\ School of Civil Engineering \& Mechanics, HuaZhong University of Science and Technology, WuHan 430074, Hubei, China \\ Correspondence should be addressed to Lifei Zheng; zhenglifei@hust.edu.cn
}

Received 7 November 2018; Revised 13 January 2019; Accepted 3 March 2019; Published 28 April 2019

Academic Editor: Victor Yepes

Copyright ( 2019 Bin Hu et al. This is an open access article distributed under the Creative Commons Attribution License, which permits unrestricted use, distribution, and reproduction in any medium, provided the original work is properly cited.

\begin{abstract}
Uneven settlement widely occurs on the roadbed under urban viaducts in operation. Previous studies focused on the effect of soft soil foundation on the uneven settlement of roadbed, without considering the phenomenon and mechanism of uneven settlement at the junction of pier cap and the roadbed under viaduct. The interaction is now considered between the buried depth of cap, the relative stiffness between cap and road subgrade, and the uneven settlement of roadbed. Using the Midas GTS NX software, a numerical analysis model of the deformation of roadbed under viaduct is constructed to study the influence of viaduct cap foundation on the uneven settlement of roadbed under viaduct. The simulated results of uneven settlement of roadbed caused by urban viaduct pier cap show that (1) when the buried depth of cap exceeds $2.35 \mathrm{~m}$, with the increase of buried depth, the fall of roadbed settlement tends to decrease, but the decreased amount is not significant. Considering the factors such as construction cost and complications of construction technology, it is suggested that the best buried depth of cap is about $2.5 \mathrm{~m}$. (2) The fall of roadbed settlement decreases with the decrease of relative stiffness between cap and roadbed. When the relative stiffness exceeds 6.3 , the decreasing trend of settlement fall is not significant. The concrete roadbed should have more stiffness in order to reduce the settlement.
\end{abstract}

\section{Introduction}

In recent years, with the rapid development of large-scale infrastructure construction and urbanization in China, construction land is increasingly scarce $[1,2]$. In order to speed up the transformation of urban expressways, urban viaducts have been constructed in modern cities. However, the viaducts in use also brought some adverse effects. Uneven settlement of roadbed occurs under a large of number viaducts in Wuhan city, deteriorating the integrity of road subgrade and causing overall or partial subsidence of the subgrade. The resultant cracking damage of roadbed lowers the driving comfort and hinders the speed of vehicle, bringing great inconvenience to driving, seriously affecting the traffic, and also posing a certain threat to the driving safety. The main form of such uneven settlement of urban roadbed is shown in Figure 1; the roadbed around viaduct cap has smaller level of settlement but that between the caps has larger level of settlement. The difference between these two levels is called settlement fall, which makes the inner side of urban road be wavy. Therefore, it is necessary to analyze and study the influence of the pier caps of urban viaduct on the uneven settlement of roadbed.

The roadbed under viaducts and the pier caps have different levels of settlement, resulting in uneven settlement on the roadbed and around the caps, which are influenced by many factors. The main causes can be summarized from two aspects: the first is the influence of the consolidation of roadbed and the second is the impact of the phenomenon called "vehicle jump." In order to ensure the safety and comfort of urban vehicle transportation, many researchers at home and abroad have done a lot of studies on the consolidation theory of soft soil foundation, which explains the uneven settlement of urban roads. For example, Terzaghi [3] conducted an unprecedented theoretical study on the consolidation process of saturated soil; based on a series of 


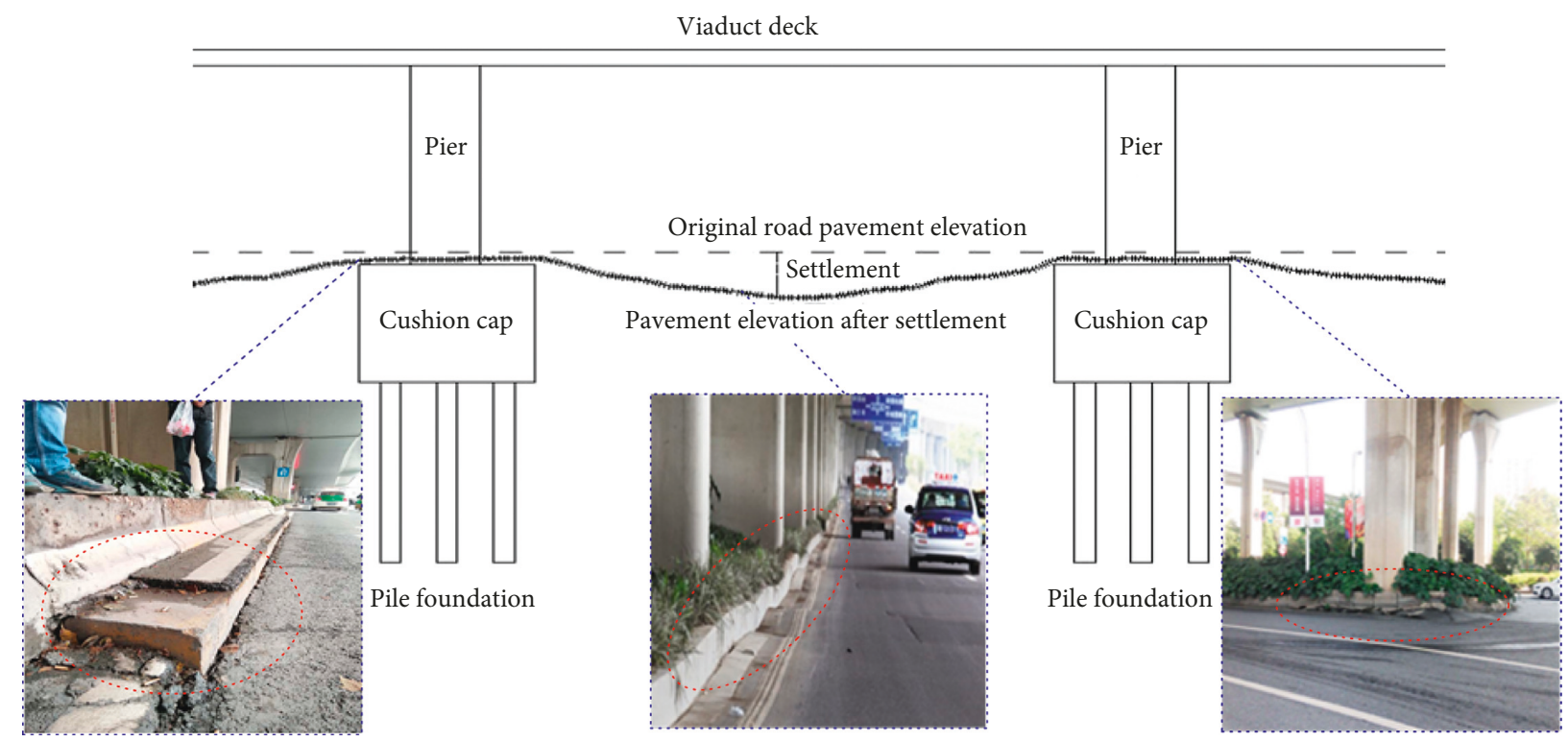

FIGURE 1: Schematic diagrams illustrating the uneven settlement of roadbed.

assumptions, the effective stress principle, and Darcy's law of infiltration, he obtained the classical one-dimensional consolidation theory of saturated soils, which lays a foundation for later studies on soil consolidation. In the next few decades, researches related to the theory of soil consolidation have been basically based on and extended from Terzaghi's consolidation theory [4]. Based on the theory put forward by Terzaghi, Biot [5] proposed a more reasonable threedimensional consolidation theory which considers the soil as a three-phase material and can be used to describe the deformation of soil more vividly and truly. The disadvantage is that there are too many factors and conditions involved in the design, so the calculation results cannot be obtained conveniently and quickly, and this theory has not been widely used until the development of computer technology.

However, there is a problem in both Terzaghi's consolidation theory and Boit's consolidation theory, i.e., the change of soil permeability is neglected, or the nonlinear variation of soil mass [6]. In fact, the soil mass cannot be considered as a body with linear deformation, and researchers started to consider this aspect slowly in 1960. Mikasa [7] put forward the limitation of Terzaghi's consolidation theory, i.e., it cannot be applied to soft clay, and he conducted a series of studies to obtain a one-dimensional nonlinear large-deformation consolidation theory of soil.

Up to now, many further studies have been conducted on subgrade settlement from the aspects of field test and monitoring. Based on the typical geological parameters of the Nanjing metrostation excavation, Li and Yan [8] numerically simulated ground surface settlements in auxiliary planes perpendicular and parallel to the excavation and in angled auxiliary planes at the excavation corner and finally developed an estimation method for building settlements. Jia et al. [9] investigated the postconstruction settlement of high-fill subgrade under gravity stress and vehicle loads and monitored the Lanzhou-Yongjing highway in situ. They analyzed the evolution of settlement with time and space, and the results show that the settlement of road shoulder is greater than that of driveway; the settlement of subgrade increases with time and tends to be stable after one year. Ling et al. [10] conducted six series of repeated load triaxial tests to evaluate the effects of the amplitude of cyclic stress, initial mean stress, and initial stress ratio on the permanent axial deformation and proposed a simplified mechanistic empirical model to predict the permanent deformation based on the product of four independent functions associated with the amplitude of cyclic stress, initial mean stress, initial stress ratio, and number of load cycles, respectively. Satisfactory predictions of the behavior of permanent deformation of coarse grained soils were obtained with this proposed model.

Most of the aforementioned studies focused on the theory of roadbed consolidation for roadbed settlement and considered the mechanism, influencing factors, settlement process, settlement time, and stress change regarding roadbed settlement. These studies provide good reference for this study. However, the influence of the pier caps of urban viaducts on the uneven settlement of road has not been considered. With the acceleration of urbanization in China, the number of viaducts is increasing over urban roads. According to the survey results of roadbed settlement near viaducts, the most serious part of uneven settlement occurs at the junction of pier cap and road. In addition, the pier caps of urban viaducts induce uneven settlement of roadbeds in a mechanism different from that in ordinary cases. The form of cap-pile foundation is widely adopted in current urban viaducts, and the settlement of pile foundation is smaller than that of the roadbed connected with the viaducts, resulting in different levels of uneven settlement at different locations. Meanwhile, the buried depth of pier cap also affects the level of roadbed settlement near the cap: the shallower is the cap, the easier it will cause large uneven settlement of roadbed. The transition section refers to the position connecting pier cap and roadbed, which have very 
different stiffness. The viaduct bridge needs a very solid foundation, so underneath the caps many piles are built going deep into the underground rock; therefore, the vertical displacement near the pier caps is very small. However, the roadbed and soil foundation are composed of loose particles, and the stiffness of roadbed is smaller than that of the viaduct, so when vehicles are running on the roadbed, the settlement deformation of the roadbed and the roadbed around the caps are not the same, aggravating the formation of settlement fall over time.

In fact, the difference between the settlement of the roadbed under viaduct and that of viaduct cap results in a large settlement fall between the roadbed and the road surrounding the cap, and the vehicles passing by may encounter the phenomenon called "vehicle jump". So far, the studies have mainly focused on analyzing the mechanism and finding prevention measures of the phenomenon called "jump off at bridge head" [11]. For example, based on practical engineering experience, Snow and Nickerson [12] used expanded polystyrene geofoam lightweight fill to mitigate settlement of bridge approach embankments. Byrum et al. [13] used geofoam (expanded polystyrene-EPS) to reduce long-term settlement of the road at bridgehead. Changwei et al. [14] proposed a new design of bridgesubgrade transition section for high-speed railways: the section of the first $2 \mathrm{~m}$ from the abutment is filled with graded gravel mixed with fly ash and cement to meet the specific stiffness and strength requirements, and the rest of the transition section is filled with roller-compacted concrete. The dynamic performance of this new type of transition section was evaluated through onsite tests and numerical analysis. Pancar and Akpinar [15] proposed an improvement method with geosynthetics (geocell + geotextile) reinforcement and compared the result with the result of lime stabilization of clayey road base soil with high water content. Zhang et al. [16] proposed an improved technique, fixed geosynthetic-reinforced, pilesupported embankment (called FGT embankment), and investigated the performance of this technique through comparative analyses and parametric studies with the finite element method (FEM). The influencing factors investigated include the elastic modulus of soil, tensile stiffness of geosynthetics, pile length, pile spacing, and pile elastic modulus. The results show that the FGT embankment can significantly reduce the settlement of embankment and enhance the stability of the embankment. Kolay et al. [17] improved the bearing capacity of silty clay soil by adding thin sand layer on the top and placing geogrids at different depths and conduced model tests for a rectangular footing resting on top of the soil to establish the load versus settlement curves of unreinforced and reinforced soil systems. The results show that the bearing capacity is increased significantly by a larger number of geogrid layers. Zhang et al. [18] carried out a series of in situ static loading tests of square footing on the geobelt-reinforced gravel cushion on soft silt. The test results show that the bearing capacity of reinforced gravel cushion is significantly larger than that of unreinforced gravel cushion, and reinforced gravel cushion has more pronounced effect of stress diffusion than unreinforced cushion.
The distribution of pressure at the bottom of reinforced gravel cushion has a saddle shape. Jaymohan and Shivashankar [19] conducted a series of laboratory-scale bearing capacity tests on a model square footing to mainly investigate the improvement of bearing capacity and reduction of settlement by a geonet reinforced granular bed (RGB) overlying weak soil as the result of prestressing the reinforcement. They investigated parameters such as the strength of the underlying weak soil, thickness of the granular bed, and magnitude and direction of prestressing force. The settlements at the interface are also measured. The addition of prestress to geonet reinforcement results in significant improvement in the load-carrying capacity and settlement response of the prestressed geonet RGB.

It is noteworthy that the aforementioned research on "jumping-off at bridge head" mainly focuses on the junction between road and bridge head and mostly adopted the method of reinforcing the abutment backfill because the main factors affecting roadbed settlement are the material properties of backfill soil such as the strength, compactness, and elastic modulus. Hence, the phenomenon and mechanism of "jumping-off" at the junction of road and pier cap has been less studied, and the influence of pier cap on roadbed settlement has not been considered. At different locations under viaducts, caps with different sizes and depths have quite different influences on the uneven settlement caused by roads, and the junction of pier cap and road is the most serious part of uneven settlement. Therefore, the mechanism of the influence of the pier cap of urban viaduct on the uneven settlement of roadbed is quite different from the common roadbed settlement.

According to the survey and statistics of roadbed settlement near viaducts, the phenomenon of uneven settlement at the junction of viaducts and roadbed is becoming more and more common, resulting in larger and larger damage loss. However, this phenomenon has not attracted widespread attention so far. At the same time, in the current design specifications, no better solution is lack to the problem of uneven settlement of roadbed under viaducts. Therefore, the uneven settlement of road under the viaduct of the Huangpu Street-Jinqiao Avenue Expressway Project in Wuhan is taken as an example in this paper to study the influence of pier cap on the uneven settlement of roadbed under urban viaduct. The Wuhan Huangpu Street-Jinqiao Avenue Expressway Project is a radial line in the Wuhan Expressway System, and it is a fast passage out of the city for the North-South link of the first ring, second ring, and third ring in the Hankou area. The total investment is 1 billion 500 million RMB-yuan, the total length is about $6,030 \mathrm{~m}$, and the width of the road is $60 \mathrm{~m}$. The whole line is built in the form of viaduct with auxiliary roads on the ground, and the elevated section is $5300 \mathrm{~m}$ long and two-way with 6 lanes, including the Zhuyeshan interchange and a cross railway bridge. However, onsite investigation until 2018 found that under the viaduct of the Huangpu Avenue-Jinqiao Avenue Expressway Project, a long distance of roadbed showed significant uplift and damage; different degrees of bulge appear on the roadbed under most piers, and the closer is the location to the viaduct pier, the higher the bulge is. At the 
same time, roadbed problems show up, such as uplift fracture, road edge deformation, cement slab voids, road edge voids, and cap exposure, as shown in Figure 1.

In sum, the novelty of this work is the research object which exited commonly, but few researchers pay attention to. In the current literature, there is little research on the uneven settlement of junction between urban viaduct and road. In the process of research, the influence of cushion cap on uneven settlement is considered, and it is also an innovation point. This paper investigates the causes of uneven settlement of roadbed under viaduct to analyze the influence of viaduct cap (at the junction with road) on uneven settlement of road. A simulation model of pier cap and roadbed is constructed to compute the influence of pier cap on the uneven settlement of roadbed numerically. The rest of this paper is organized as follows: Section 2 introduces the mathematical theory of uneven settlement of roadbed and constitutive model; Section 3 introduces the finite element modeling method used in this study and the calculation parameters; Section 4 introduces and discusses the influence of the buried depth of cap $(H)$ on the uneven settlement of roadbed; Section 5 analyzes the influence of the relative stiffness between pier caps and roadbed on the uneven settlement of the roadbed; finally, Section 6 summarizes the conclusions of this study.

\section{Mathematical Theory of Uneven Settlement}

The layered summation method is commonly used to calculate roadbed settlement. The roadbed is filled layer by layer, and the settlement process is related to this layered filling process. In the calculation, it is assumed that the embankment is filled in $m$ layers filling from bottom to top; among them, the height of the first layer is $h_{i}$ and the gravity is $\gamma_{i}$. The $i$ th layer of soil only bears the self-weight load of each layer above the $(i+1)$ th layer of soil (including the $(i+1)$ th layer). The self-weight load is calculated by the weight of soil column, and $K$ is any calculated filling layer greater than $i$. Let $t$ be the calculation time and the zero of $t$ be the time when the first layer of soil has just been filled. In the calculation, the settlement of each layer of soil under the action of the upper earth pressure can be calculated. According to the above analysis, the calculation formula is selected as follows:

$$
\varepsilon=\frac{t}{C \sigma^{M}+D \sigma^{N} t}
$$
to be

The consolidation strain and stress of the ith layer are set

$$
\begin{aligned}
\varepsilon_{i} & =\frac{t-t_{K}}{C_{i} \sigma_{i}^{M_{i}}+D_{i} \sigma_{i}^{N_{i}}\left(t-t_{K}\right)}, \\
\sigma_{i} & =\sum_{j=i+1}^{K} h_{j} \gamma_{j} .
\end{aligned}
$$

The total settlement at time $t$ of the filled soil below the Kth layer is

$$
S=\sum_{i=1}^{K-1} \varepsilon_{i} h_{i}, \quad 2 \leq K \leq m, t_{K+1}>t \geq t_{K} \geq t_{2},
$$

where $S_{j}$ is the deformation of the $i$ th layer of soil, $\varepsilon_{i}$ is the strain of the $i$ th layer of soil, $h_{i}$ and $h_{j}$ are the thicknesses of the $i$ th and $j$ th layer of soil, respectively, $t_{k}$ is the time when the $k$ th layer of soil is filled, $\gamma_{j}$ is the bulk density of the $j$ th layer of soil, $C_{i}, D_{i}, M_{i}$, and $N_{i}$ are the testing parameters of the $i$ th layer of soil, $k$ is the number of layered filled before time $t, m$ is the total number of filled soil layers, and $i, j$, and $k$ are the number of layers and $k>j>i$.

Because the pile foundation of bridge is located in deeper bedrock, which has greater rigidity, after the completion of the bridge, it is generally believed that the settlement of the pile foundation and pier cap is completed. Therefore, the settlement of pier cap is neglected in this study.

Coulomb put forward in 1776 the strength equation of soil failure: $\tau_{f}=c+\sigma \tan \varphi$. In 1900, Mohr gave a strength equation: $\tau_{f}=f(\sigma)$. According to this criterion, material failure occurs when the maximum molar circle of the stress state of the material is tangent to the envelope represented by the above formula. The shear strength of the material is related to the normal stress acting on the plane, and material damage is not caused by the maximum shear stress, but the most dangerous combination of " $\tau-\sigma$ " on the plane, as shown by the stress invariance in Formula (4). It appears as an irregular 6-surface vertebral body in the principal stress space, an irregular hexagon shape in the cross section of the $\pi$ plane, and an opening angle on the 3 -axis plane:

$$
\begin{gathered}
p \sin \varphi+\frac{1}{\sqrt{3}} q\left[\frac{1}{\sqrt{3}} \sin \theta \sin \varphi-\cos \theta\right]+c \cos \theta=0, \\
p=\frac{\sigma_{1}+\sigma_{2}+\sigma_{3}}{3}, \\
q=\frac{1}{\sqrt{2}}\left[\left(\sigma_{1}-\sigma_{2}\right)^{2}+\left(\sigma_{2}-\sigma_{3}\right)^{2}+\left(\sigma_{3}-\sigma_{1}\right)^{2}\right]^{1 / 2}
\end{gathered}
$$

The constitutive relation adopted in this paper is the Mohr-Kulun constitutive equation modified by Midas, who improved the classical Mohr-Kulun constitutive equation, and this constitutive equation can more accurately simulate all kinds of foundation. It can be used to better simulate linear and nonlinear, elastic and elastic-plastic models, and their combinations [20]. As shown in Figure 2, although the modified Mohr-Coulomb constitutive model and the Mohr-Coulomb constitutive model are the same on the yield surface, they differ in that the modified MohrCoulomb constitutive model adopts the double hardening structure for shear deformation and compression; moreover, the yield surfaces of shear deformation and compression are not uniform, but independent of each other.

The modified Mohr-Coulomb constitutive model takes special measures to deal with the partial plane and solves the instability problem in the calculation process, so better convergence effect is achieved. The modified constitutive law adopts the principle of associated flow rule in the $p$ - $q$ plane 


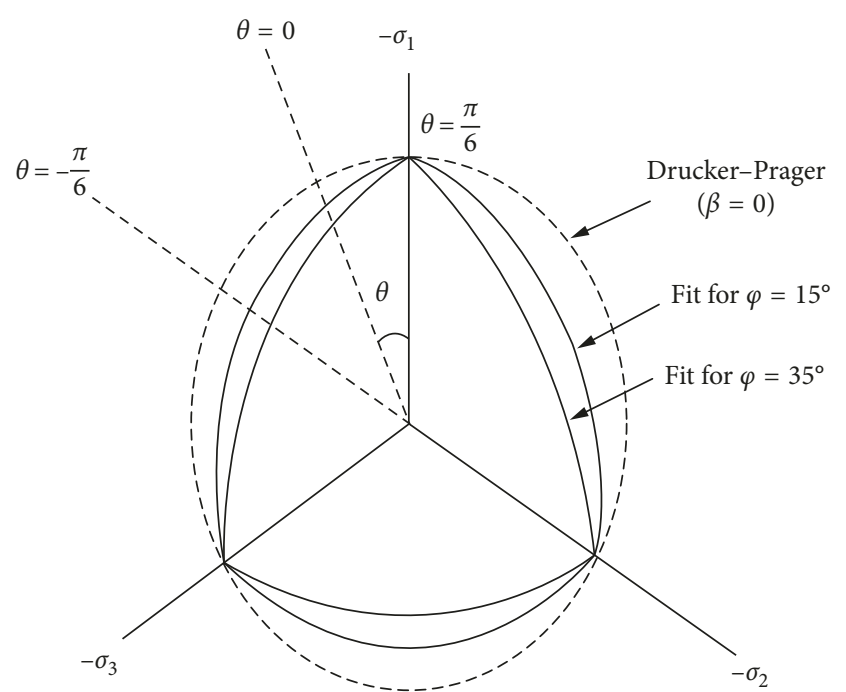

Figure 2: The partial plane.

and the principle of nonassociated flow rule in the partial plane. As shown in Figure 3, both the state of cohesion in the classical constitutive law and the relationship between stress and strain can be included after " $\Delta p$ " is used. The strength of rock and soil is described by the secant stiffness of the 3-axis test $\left(E_{50 \text { ref }}\right)$, unloading elastic modulus $\left(E_{\text {urref }}\right)$, and tangent stiffness $\left(E_{\text {oedref }}\right)$ from the principal compression and compaction test, so the foundation model can be more accurately constructed.

The modified Mohr-Coulomb constitutive model can be used to simulate the combined nonlinear-elastic and elastoplastic model observing the power-law relation and can be applied to more extensive types of soil than the Moore-Kulun law, especially materials with frictional properties, such as sand or concrete. The yield in the modified MC model is a double hardening model with no interaction between the shear yield and compressive yield. In the partial plane, it can be expressed as a Mohr-Coulomb equation, as shown in the following formula:

$$
\begin{aligned}
& f_{1}=\frac{q}{R_{1}(\theta)}-\frac{6 \sin \phi}{3-\sin \phi}(p+\Delta p), \\
& f_{2}=(p+\Delta p)^{2}+\alpha\left[\frac{q}{R_{2}(\theta)}\right]^{2}-p_{c}^{2},
\end{aligned}
$$

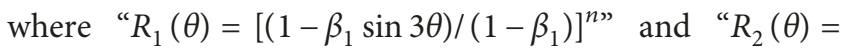
$\left[\left(1-\beta_{2} \sin 3 \theta\right) /\left(1-\beta_{2}\right)\right]^{n \text { " }}$ represent the differences in the 3axis compressive and 3 -axis tensile strength, respectively.

In this paper, the entity element is used in the computational model. The solid elements have translational degrees of freedom in the $x, y$, and $z$ axes of the global coordinates (GCS):

$$
u_{i}=\left\{\begin{array}{lll}
u_{i} & v_{i} & w_{i}
\end{array}\right\} .
$$

The stress and strain vectors are represented as follows:

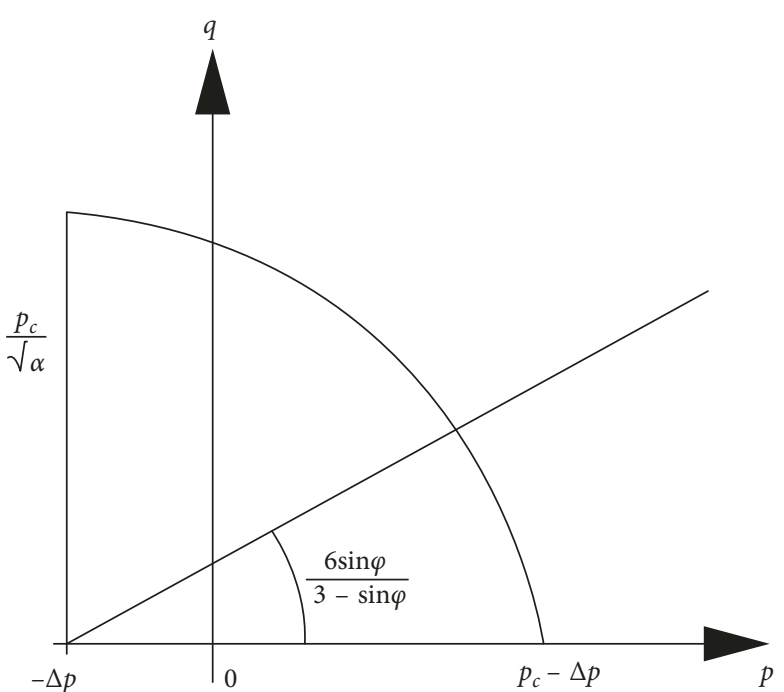

Figure 3: The $p$ - $q$ plane.

$$
\begin{gathered}
\boldsymbol{\sigma}=\left\{\begin{array}{c}
\sigma_{x x} \\
\sigma_{y y} \\
\sigma_{z z} \\
\tau_{x y} \\
\tau_{y z} \\
\tau_{z x}
\end{array}\right\}, \\
\boldsymbol{\varepsilon}=\left\{\begin{array}{c}
\varepsilon_{x x} \\
\varepsilon_{y y} \\
\varepsilon_{z z} \\
\gamma_{x y} \\
\gamma_{y z} \\
\gamma_{z x}
\end{array}\right\} .
\end{gathered}
$$

\section{Computation and Modeling Method}

3.1. Model Construction Steps. Figure 4 shows the whole computational model, in which the stratigraphic structure method is used to divide the soil from top to bottom into 5 layers: miscellaneous fill, clay, silty clay, silty sand, and sandstone. The width, depth, and length of the model are $120 \mathrm{~m}, 80 \mathrm{~m}$, and $120 \mathrm{~m}$, respectively. In order to more accurately simulate the deformation of roadbed, the pier of viaduct in the model adopts the form of single pier. The whole model has three spans, with each span $30 \mathrm{~m}$ long; the height of each pier is $15 \mathrm{~m}$, the thickness of pier cap is $3 \mathrm{~m}$, the length of the pile foundation under each cap is $45 \mathrm{~m}$, and the width of the roadbed under the viaduct is $40 \mathrm{~m}$. In this model, solid elements are used to simulate each oil layer, viaduct, and road structures. The interaction between pile foundation and soil is considered in the calculation in order to match the simulation with the actual situation. The beam element is used to simulate the pile foundation, whose cross 


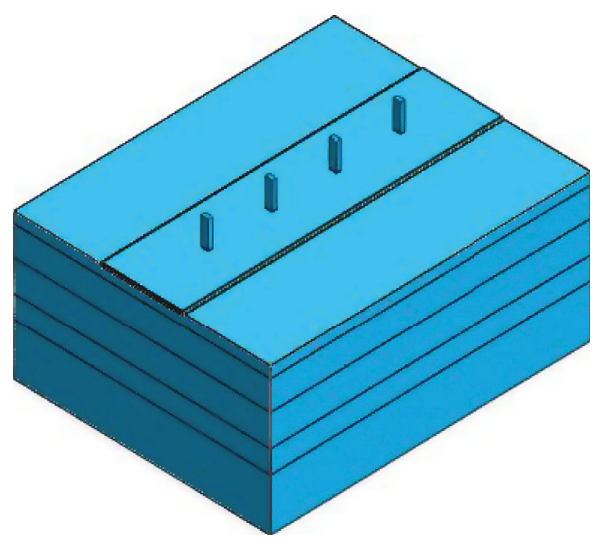

(a)

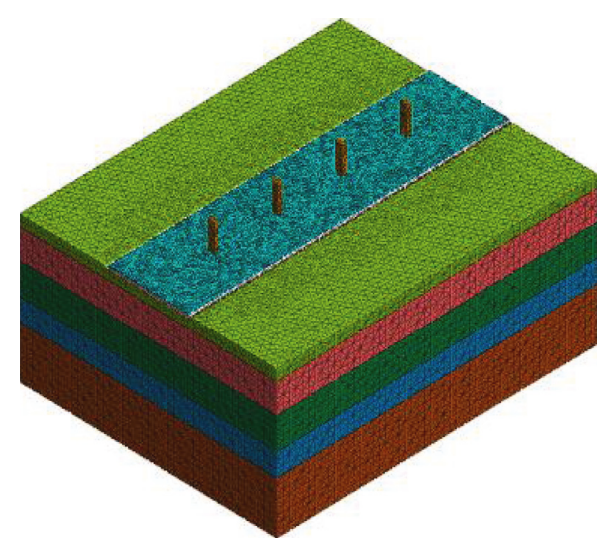

(b)

FIGURE 4: Numerical model for analyzing the deformation of roadbed under viaduct. (a) Real body. (b) Grids.

section is a circle with diameter of $1.8 \mathrm{~m}$. The stiffness around the pile interface and that at the pile end is defined to simulate the friction and relative displacement between the pile and the adjacent soil. The motion of the interface elements of pile can be divided into two parts: normal and tangential components. It is assumed that the normal motion is the coordinated deformation of pile interface and soil elements, and the tangential motion is regarded as a nonlinear elastic behavior. The ultimate shear force of pile interface material is $650 \mathrm{kN} / \mathrm{m}^{2}$, shear stiffness modulus is $50,000 \mathrm{kN} / \mathrm{m}^{3}$, normal stiffness modulus is $500,000 \mathrm{kN} / \mathrm{m}^{3}$, the bearing capacity of pile end is $4,000 \mathrm{kN}$, and the spring stiffness of pile end is $16,000 \mathrm{kN} / \mathrm{m}^{2}$.

In order to observe the deformation of the roadbed near caps more clearly, the bridge deck of viaduct is omitted and the load over the deck is equivalently applied to the pier. The numerical model can be constructed in the following steps: (1) run the Midas GTS NX program; (2) import the CAD line box file; (3) input material parameters; (4) expand solid bodies and divide them; (5) size control of solid bodies; (6) divide grids and check grid quality; (7) set boundaries and loads; (8) add construction stages; (9) carry out the analyses of working conditions; and (10) complete the model construction. The constructed model is shown in Figure 3. Besides, in the process of modeling, attention should be paid to clear the displacements before analysis.

3.2. Pile Element and Pile-Soil Interface Element. When setting up pile elements in the three-dimensional solid model, embedded beam element is used to directly consider the connection characteristics with the surrounding elements.

The inclined stiffness matrix of the solid-beam contact element is as follows:

$$
K_{t}=\sum_{l=1}^{n p} B^{l^{T}} T B^{l} W_{l} \operatorname{det} J_{l},
$$

where $K_{t}$ is the inclined rigidity, $W_{l}$ is the weight, and $T$ is the relative displacement-friction relation matrix.
There are two types of material constitutive models for pile elements: linear elastic and nonlinear elastic materials. The relative displacement-friction matrix is

$$
\mathbf{D}=\left[\begin{array}{ccc}
k_{n} & 0 & 0 \\
0 & k_{s} & 0 \\
0 & 0 & k_{s}
\end{array}\right] .
$$

The normal stress $(\sigma)$ and shear stress $(\tau)$ can be calculated by the constitutive relation, and the stress of a threedimensional structure has one normal stress and two tangential forces:

$$
\left\{\begin{array}{c}
\Delta \sigma \\
\Delta \tau \\
\Delta \tau
\end{array}\right\}=\mathbf{D}\left\{\begin{array}{c}
\Delta \varepsilon \\
\Delta \gamma \\
\Delta \gamma
\end{array}\right\} .
$$

The behavior of pile-soil interface elements refers to the behavior of interface between solid elements and the pile, which can be examined in two normal directions and one tangential direction. The shear/normal stiffness is defined to simulate the interface behavior. Rigid-body movement is assumed in two normal directions, which is consistent with the soil element. In the tangential direction, nonlinear elastic motion is assumed.

The pile interface elements and the pile end interface elements represent the nonlinear behavior through stiffness and bearing capacity or ultimate strength. When the shear stiffness of pile interface is defined by the yielding strength, as shown in Figure 5, it is assumed that the yielding strength and the slope based on height change follow a completely elastic-plastic behavior. When the stiffness is defined as a function, the displacement-friction curve can be defined by height.

3.3. Selection of Parameters. In the calculation model of this paper, the displacement at the bottom of roadbed foundation is set to be 0 , i.e., $x=0, y=0$, and $z=0$. At the lateral sides, $x=0$ and $y=0$. The self-weight load of each structural layer is applied based on the material weight. The road vehicle load is equivalent to a uniform load of $15 \mathrm{kPa}$, and 


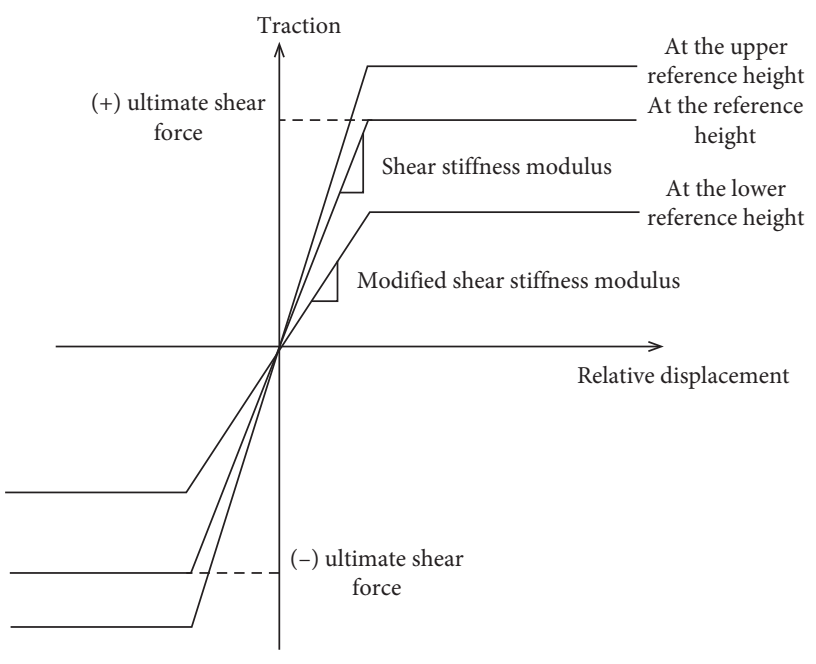

Figure 5: Relative displacement-traction.

the bridge deadweight and the vehicle load on the bridge deck are also equivalent to an uniform load of $1865 \mathrm{kN} / \mathrm{m}^{2}$ acting on the pier.

The parameters in the proposed model are selected based on the data obtained from the geological exploration for the Wuhan Huangpu Street-Jinqiao Avenue Expressway Project, involving the soil type, thickness, gravity, friction angle, cohesion, Poisson's ratio, modulus, and so on. The specific parameters of the model are shown in Tables 1 and 2.

\section{Analysis of the Effect of Pier Cap on the Uneven Settlement of Roadbed}

The aforementioned model and calculation parameters are used for simulation modeling, and the buried depths of " $H=0.2,0.85,1.35,1.85,2.35$, and $2.85 \mathrm{~m}$ " are calculated alternately in the model. The buried depth of cap refers to the height from the road surface to the upper surface of the pier cap. In the calculation, the directions of coordinate axes are defined as follows: the $X$ axis is horizontal and perpendicular to the direction of driving and is defined as the transverse direction of the road; the $Y$ axis is in another horizontal direction and parallel to the driving direction and is defined as the longitudinal direction of the road; the $Z$ axis is vertical, with the vertical, upward direction as the normal direction. The simulated results are shown in the form of nephogram in Figures 6-10.

\subsection{Transverse Variation of Roadbed Settlement. Figure 6} shows the nephograms of a transverse section of roadbed settlement, in which the marked locations on the road correspond to the $\mathrm{A}$ and $\mathrm{B}$ points in the schematic diagram in Figure 11. The calculated results are listed in Table 3.

The data shown in Figure 6 and Table 3 indicate that the road is relatively uplifted at the caps, and significant settlement is found on both sides of the road. As the buried depth of cap is larger, roadbed settlement gets greater adjacent to the caps and on both sides of the road, but there is a slight decrease in the settlement fall between them. When the buried depth of cap is between 1.85 and $2.35 \mathrm{~m}$, the fall of roadbed settlement decreases significantly, but the overall change is not significant.

The level of settlement fall directly determines the stress state of roadbed structure. In order to determine the influence of settlement fall on the stress of roadbed structure, it is necessary to classify differential settlement, and different treatment measures corresponding to the level of settlement fall can then be taken in practical engineering to suppress the settlement to be within the permissible extent to satisfy the performance of roadbed structure and realize active control of differential settlement [21]. In determining the target for the control of settlement fall, the tensile strength and fatigue characteristics are taken into account simultaneously of the material used as roadbed structure layer. The two properties impose different requirements for settlement fall. When the tensile strength of material is considered in the requirement, the allowed settlement fall is greater; it is smaller when material fatigue is considered in the requirement. Hence the allowed rate of slope change satisfying the required fatigue performance of material can be regarded as the lower limit of standard settlement fall control, and the rate of slope change satisfying the required tensile-strength performance can be taken as the higher limit of standard settlement fall control. According to the lower limit, higher limit, and standard control of settlement fall, the settlement fall of roadbed can be classified into 4 grades: slight, low, medium, and high, as shown in Table 4 [22].

When the settlement fall belongs to the two lower grades of "slight" and "low", the additional stress induced by the differential settlement of subgrade in the structural layer of roadbed is small, so structural damage will not occur in the roadbed. The smoothness of roadbed will be preserved, and only light or no treatment is needed. When the differential settlement belongs to the "medium" grade, the additional stress induced by the settlement fall of roadbed in the structure layer of roadbed will lead to damage in the roadbed structure, so it is necessary to take engineering measures to reduce the amount of settlement and make the estimated postconstruction settlement be smaller than the allowable postconstruction settlement. When the differential settlement belongs to the "high" grade, the differential settlement of roadbed has a more serious impact on the roadbed structure, and improper treatment will cause early damage to the roadbed structure. Therefore, in this paper, the "medium" grade of settlement fall is taken as the control target.

In the process of uneven settlement caused by pier cap, the buried depth " $H$ " has a great influence on the transverse settlement fall of roadbed, and those higher than $70 \mathrm{~mm}$ belong to the "high" grade, as shown in Table 3. The relationship between the transverse settlement fall of roadbed under urban viaducts and the buried depth of pier cap is shown in Figure 7. The functional relationship between the maximum transverse settlement fall $\Delta s$ and the buried depth $H$ of cap can be expressed as follows:

$$
\Delta s=-0.5621 H^{2.772}+75.57
$$


TABLe 1: Parameters for soil mass calculation.

\begin{tabular}{|c|c|c|c|c|c|c|c|c|c|c|}
\hline \multirow{2}{*}{ Category } & \multicolumn{10}{|c|}{ Parameter } \\
\hline & $h(\mathrm{~m})$ & $\gamma\left(\mathrm{kN} / \mathrm{m}^{3}\right)$ & $E_{50 \mathrm{ref}}\left(\mathrm{kN} / \mathrm{m}^{2}\right)$ & $E_{\text {oedref }}\left(\mathrm{kN} / \mathrm{m}^{2}\right)$ & $E_{\text {urref }}\left(\mathrm{kN} / \mathrm{m}^{2}\right)$ & $\mu$ & $e_{0}$ & $n$ & $\varphi\left({ }^{\circ}\right)$ & $c\left(\mathrm{kN} / \mathrm{m}^{2}\right)$ \\
\hline Miscellaneous fill & 5 & 17 & 4500 & 4500 & 13,500 & 0.35 & 0.3 & 0.3 & 18 & 8 \\
\hline Clay & 13 & 17.7 & 8000 & 8000 & 24,000 & 0.35 & 0.4 & 0.2 & 12 & 24 \\
\hline Silty clay & 14 & 17.7 & 15,000 & 15,000 & 45,000 & 0.33 & 0.3 & 0.2 & 21 & 15 \\
\hline Silty sand & 10 & 19.4 & 8000 & 8000 & 24,000 & 0.30 & 0.25 & 0.3 & 33 & 1 \\
\hline Sandstone & 23 & 21.8 & 75,000 & 75,000 & 225,000 & 0.20 & 0.5 & 0.3 & 35 & 400 \\
\hline
\end{tabular}

Note: $h$ : thickness; $\gamma$ : gravity; $E_{50 \text { ref }}$ : the secant stiffness of the 3 -axis test; $E_{\text {oedref }}$ : the tangent stiffness $\left(E_{\text {oedref }}\right)$ from the principal compression and compaction test; $E_{\text {urref }}$ : unloading elastic modulus; $\mu$ : Poisson's ratio; $e_{0}$ : initial pore ration; $n$ : porosity; $\varphi$ : friction angle; $c$ : cohesion.

TABLE 2: Parameters for structural member calculation.

\begin{tabular}{lcccc}
\hline \multirow{2}{*}{ Category } & \multicolumn{3}{c}{ Parameter } \\
& Thickness (height) $(\mathrm{m})$ & Gravity $\gamma\left(\mathrm{kN} / \mathrm{m}^{3}\right)$ & Poisson's ratio $\mu$ & Elastic modulus $(\mathrm{MPa})$ \\
\hline Road surface & 0.2 & 27 & 0.35 & 3000 \\
Base layer & 0.65 & 26 & 0.25 & 4500 \\
Cushion layer & 1 & 26 & 0.30 & 840 \\
Pier & 15 & 25 & 0.20 & 31,500 \\
Cap & 3 & 25 & 0.20 & 31,500 \\
Pile & 45 & 25 & 0.20 & 33,500 \\
\hline
\end{tabular}

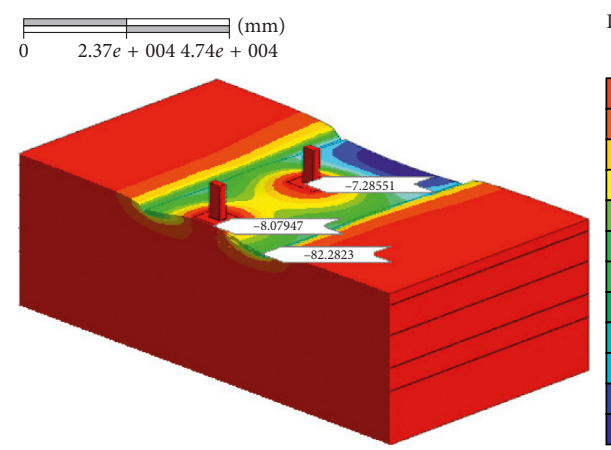

(Data) analysis of the effect, road operations, incr $=1($ load $=1.000)$, (unit $) \mathrm{kN}, \mathrm{mm}$

(a)

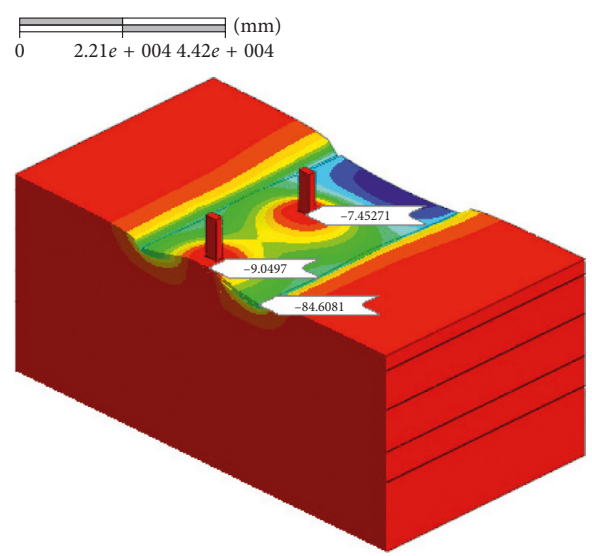

(Data) analysis of the effect, road operations, incr $=1($ load $=1.000),($ unit $) \mathrm{kN}, \mathrm{mm}$
Displacement $T Z(\mathrm{~mm})$

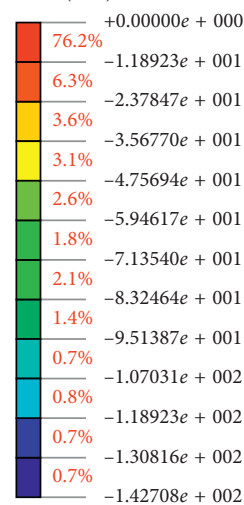

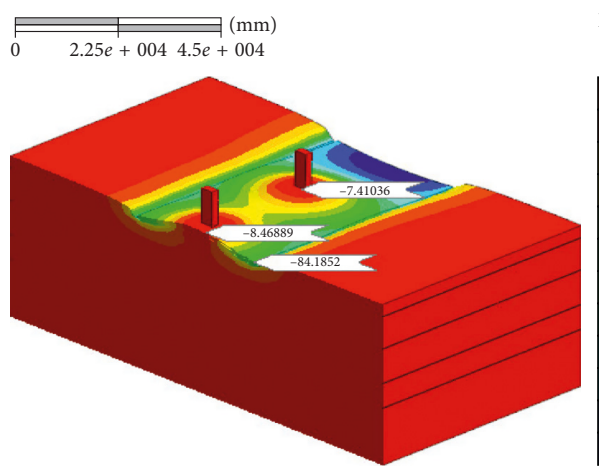

(Data) analysis of the effect, road operations, incr $=1($ load $=1.000)$, (unit) $\mathrm{kN}, \mathrm{mm}$

(b)

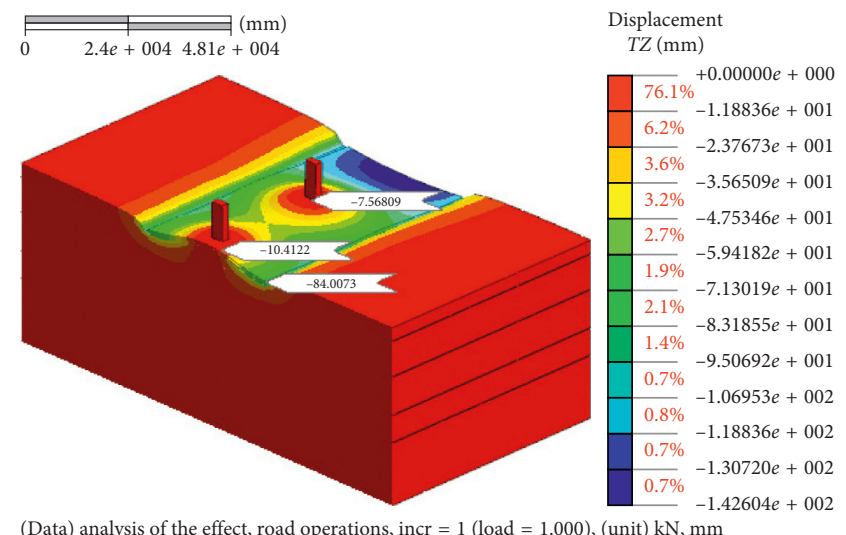

(c)

(d)

Figure 6: Continued. 


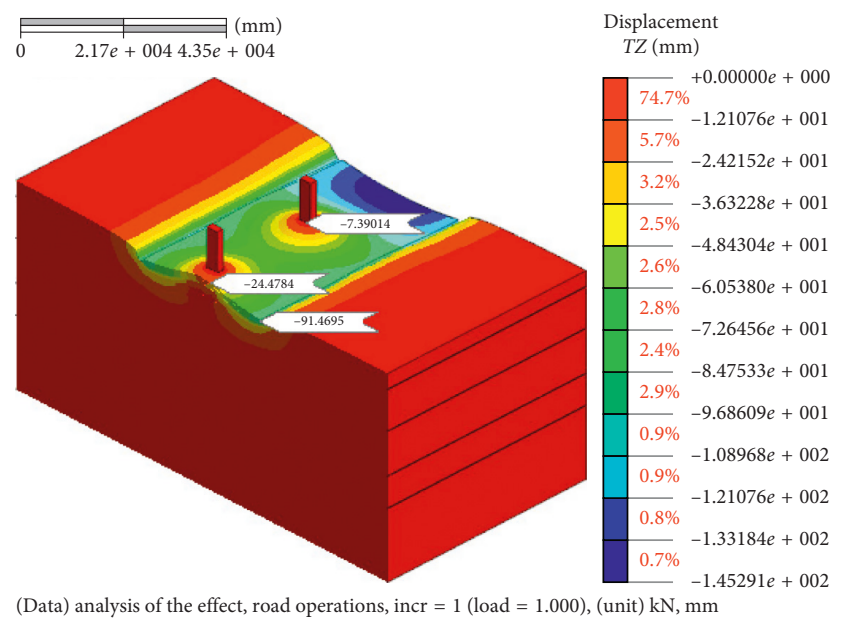

(e)

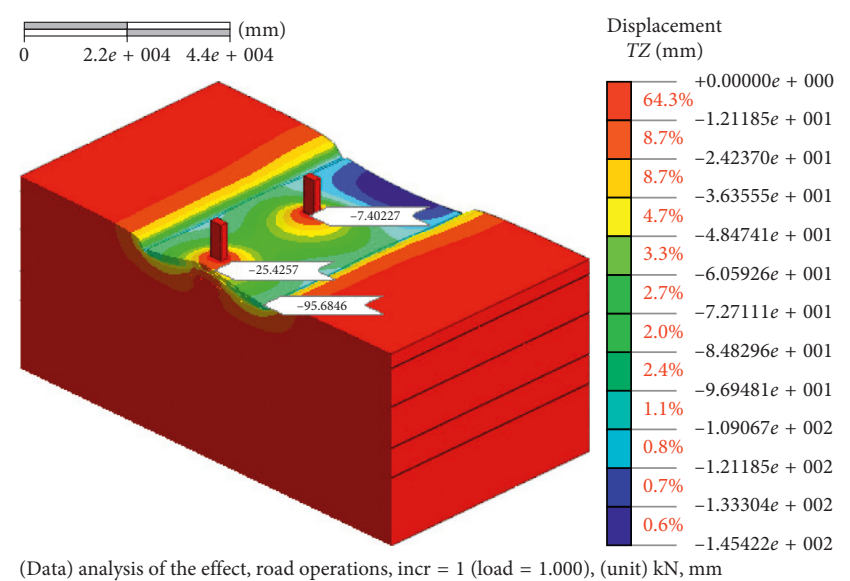

(f)

Figure 6: Transverse section of roadbed settlement for different buried depths of cap. (a) $H=0.2 \mathrm{~m}$. (b) $H=0.85 \mathrm{~m}$. (c) $H=1.35 \mathrm{~m}$. (d) $H=1.85 \mathrm{~m}$. (e) $H=2.35 \mathrm{~m}$. (f) $H=2.85 \mathrm{~m}$.

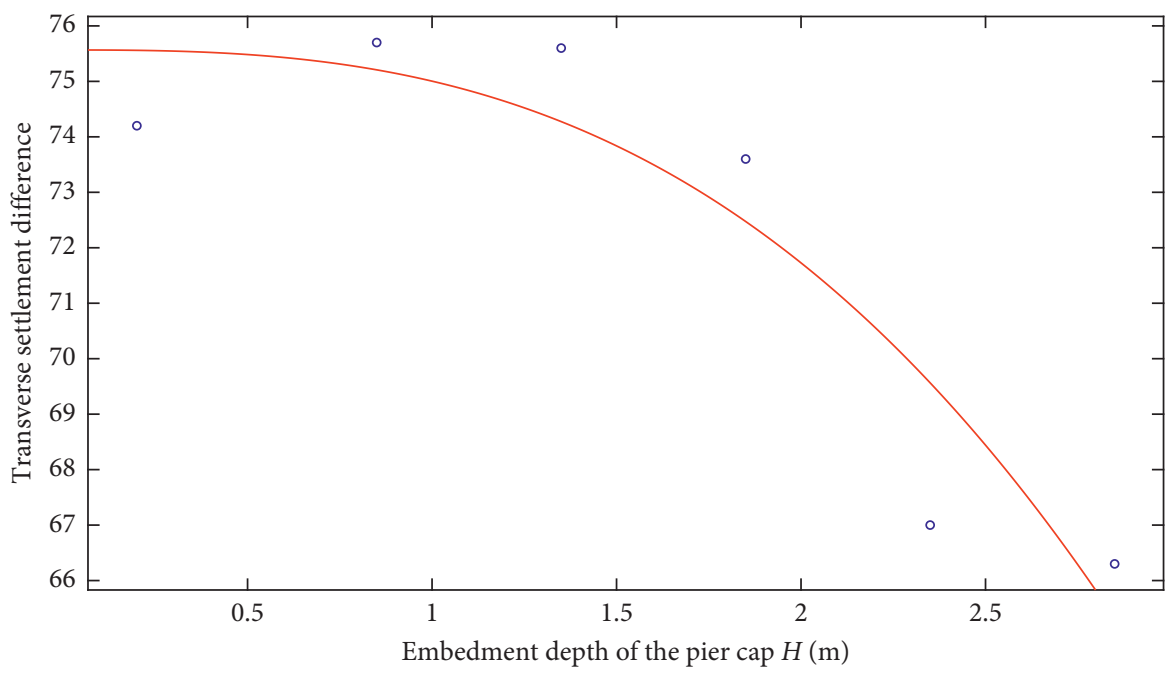

Figure 7: The maximum transverse settlement fall of roadbed under viaduct versus the buried depth of cap.

In order to ensure the service performance of highway under urban viaducts, the design specifications relevant to Table 4 require that the maximum transverse fall of roadbed settlement shall not be more than $70 \mathrm{~mm}$. According to the above calculation, the buried depth of cap shall be greater than $2.28 \mathrm{~m}$. Therefore, when a viaduct is built on the road subgrade, the buried depth of viaduct cap should be within the range of $2.28-2.85 \mathrm{~m}$, which helps to control the maximum transverse settlement fall of roadbed under the viaduct and ensure the service performance of the road under the viaduct.

\subsection{Longitudinal Variation of Roadbed Settlement.} Figure 8 shows the nephogram of a longitudinal section of roadbed settlement, in which the positions marked on the road correspond to the $\mathrm{C}$ and $\mathrm{D}$ points in Figure 11, and the calculated results are listed in Table 5. From Figure 8 and
Table 5, it can be seen that the longitudinal deformation of roadbed is wavy, i.e., relatively uplifted at the caps and more significantly subsided in the middle of adjacent caps; with the increase of the buried depth of cap " $H$ ", the settlement fall of roadbed gradually decreases.

During the period when the uneven settlement of roadbed is affected by pier cap, the buried depth of cap " $H$ " has little effect on the longitudinal settlement fall, resulting in settlement fall not more than $50 \mathrm{~mm}$, belonging to the "low" grade according to Table 4. However, as shown in Figure 9, the relationship between the longitudinal settlement fall of roadbed under urban viaducts and the buried depth of cap " $H$ " is as follows:

(1) When the buried depth of cap is less than $0.85 \mathrm{~m}$, with the increase of the buried depth of cap, the decrease of settlement fall is not significant. 


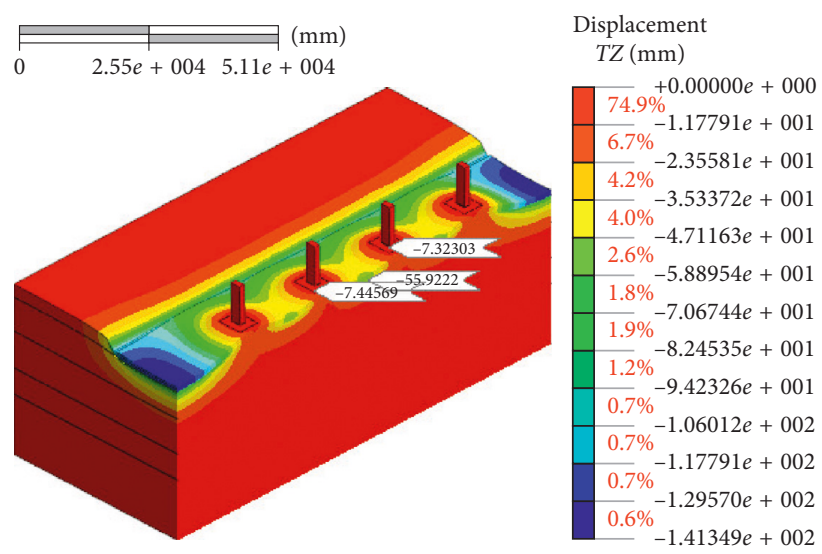

(Data) analysis of the effect, road operations, incr $=1($ load $=1.000)$, (unit) $\mathrm{kN}, \mathrm{mm}$

(a)

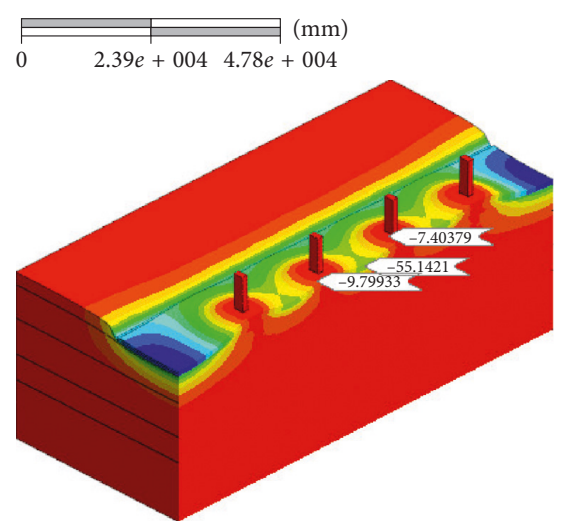

$T Z(\mathrm{~mm})$

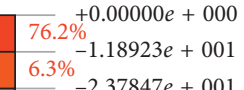

$3.6 \%{ }^{-2.37847 e+001}$

$3.1 \%-3.56770 e+001$

$2.6 \%-4.75694 e+001$

$1.8 \%{ }^{-5.94617 e+001}$

$-7.13540 e+001$

$1.4 \%-8.32464 e+001$

$0.70 .51387 e+001$

$0.8 \%-1.07031 e+002$

$0.7 \%-1.18923 e+002$

$-1.42708 e+002$
(Data) analysis of the effect, road operations, incr $=1$ (load $=1.000)$, (unit) $\mathrm{kN}, \mathrm{mm}$ (c)

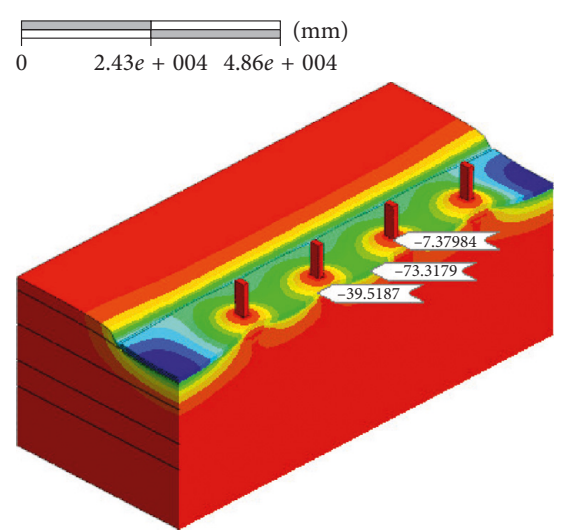

Displacement $T Z(\mathrm{~mm})$

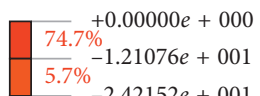

$-1.30816 e+002$

(Data) analysis of the effect, road operations, incr $=1$ (load $=1.000)$, (unit) $\mathrm{kN}, \mathrm{mm}$

(e)

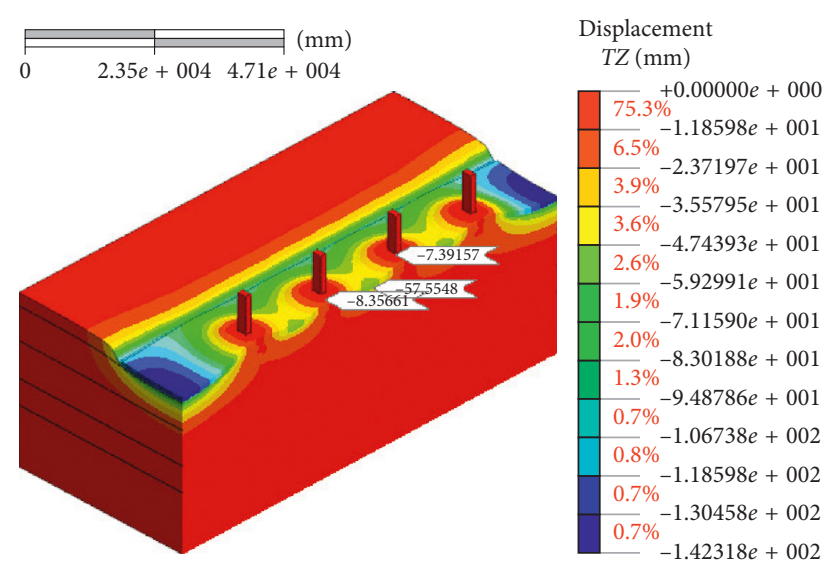

(Data) analysis of the effect, road operations, incr $=1($ load $=1.000)$, (unit) $\mathrm{kN}, \mathrm{mm}$

(b)

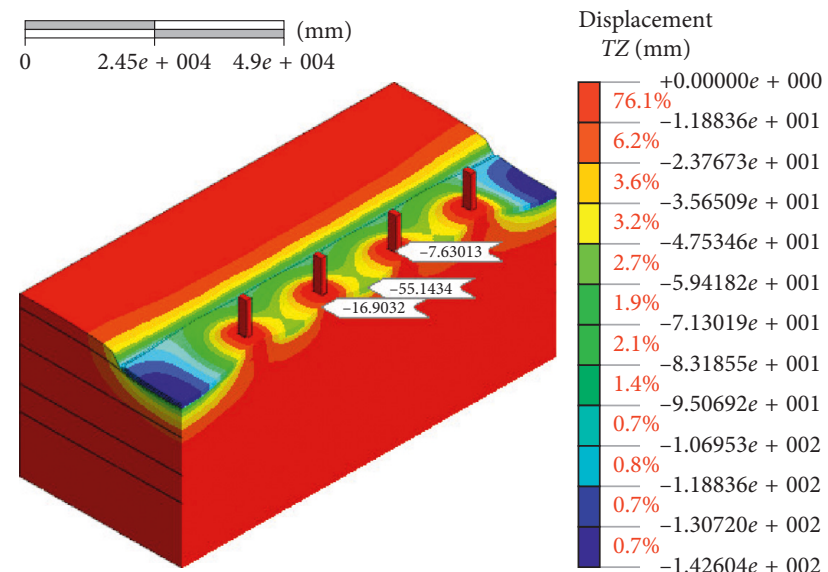

(Data) analysis of the effect, road operations, incr $=1$ (load $=1.000)$, (unit) $\mathrm{kN}, \mathrm{mm}$

(d)

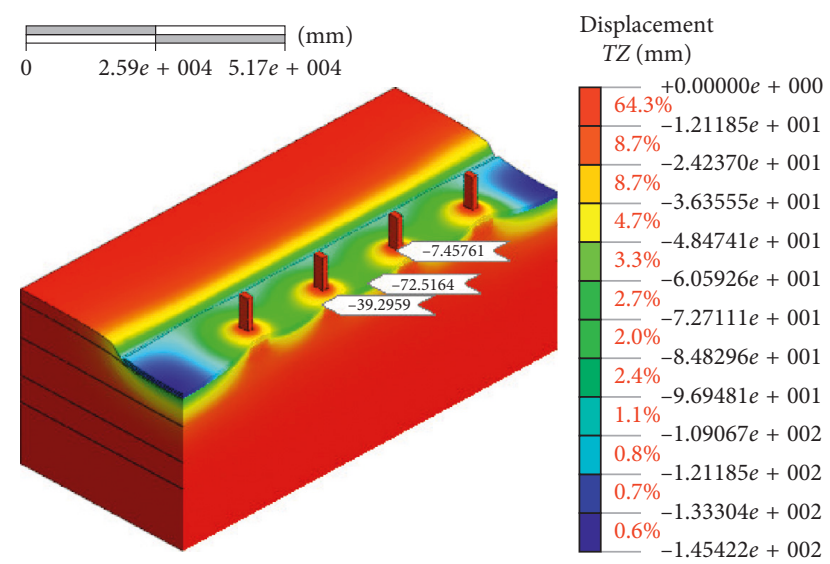

(Data) analysis of the effect, road operations, incr $=1($ load $=1.000)$, (unit) $\mathrm{kN}, \mathrm{mm}$

(f)

Figure 8: Longitudinal section of roadbed settlement for different buried depths of cap. (a) $H=0.2 \mathrm{~m}$. (b) $H=0.85 \mathrm{~m}$. (c) $H=1.35 \mathrm{~m}$. (d) $H=1.85 \mathrm{~m}$. (e) $H=2.35 \mathrm{~m}$. (f) $H=2.85 \mathrm{~m}$.

(2) When the buried depth of cap is in the range of $0.85-2.35 \mathrm{~m}$, with the increase of buried depth, the settlement fall decreases significantly and the decreased amount is large.
(3) When the buried depth of cap exceeds $2.35 \mathrm{~m}$, with the increase of buried depth, the decrease of settlement fall is not significant. Moreover, in the actual construction process, the larger is the 


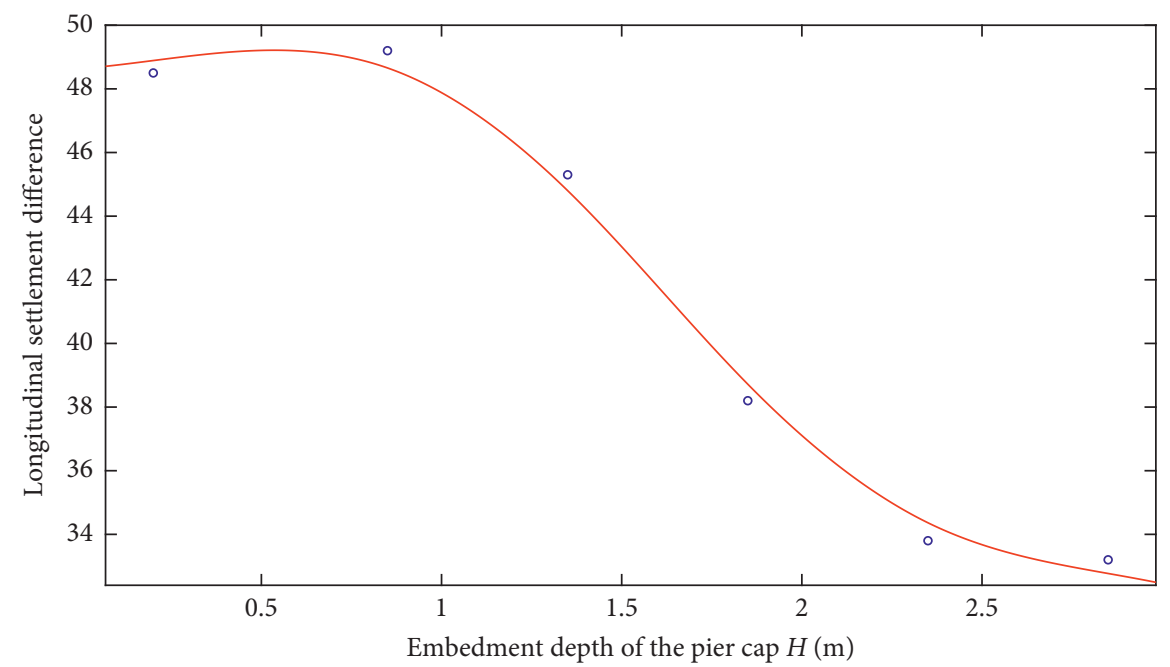

FIgUre 9: Relationship between the longitudinal settlement fall and buried depth of cap.

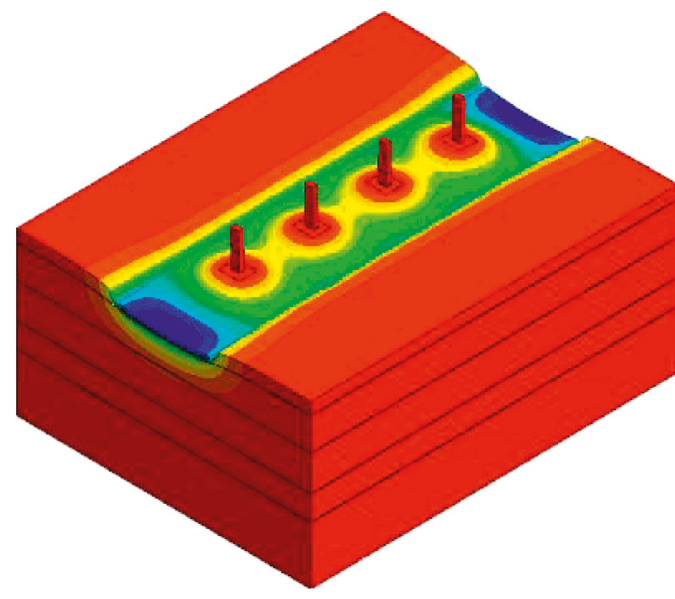

(a)

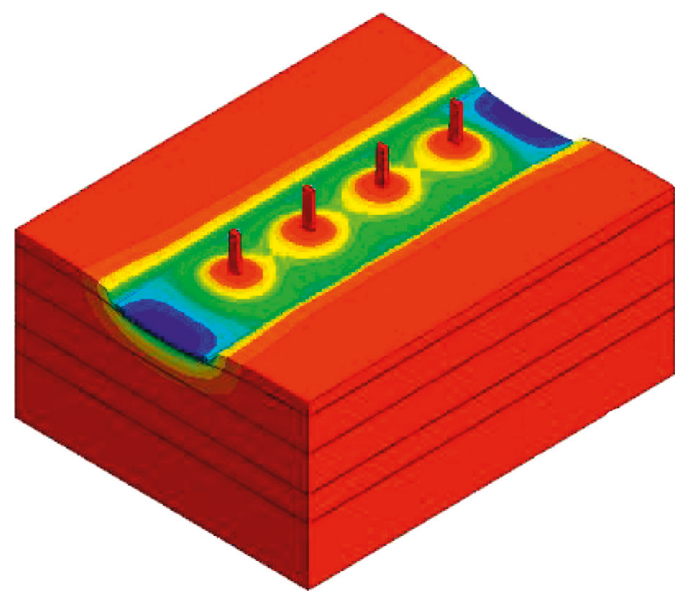

(c)

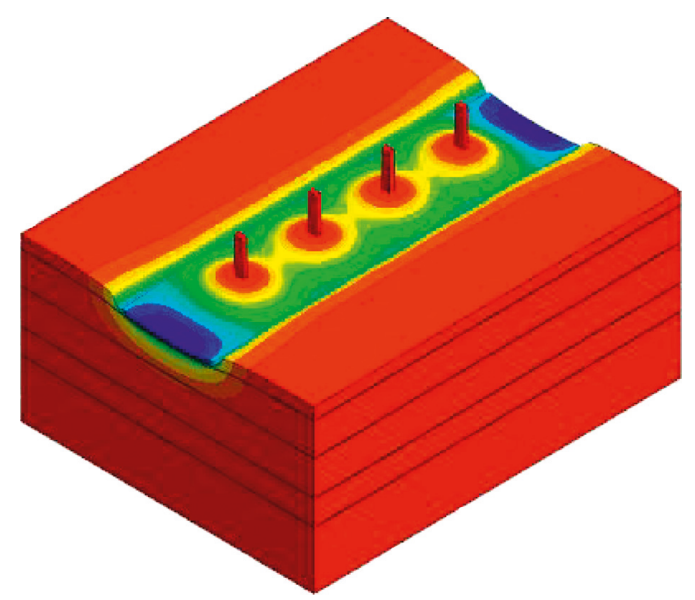

(b)

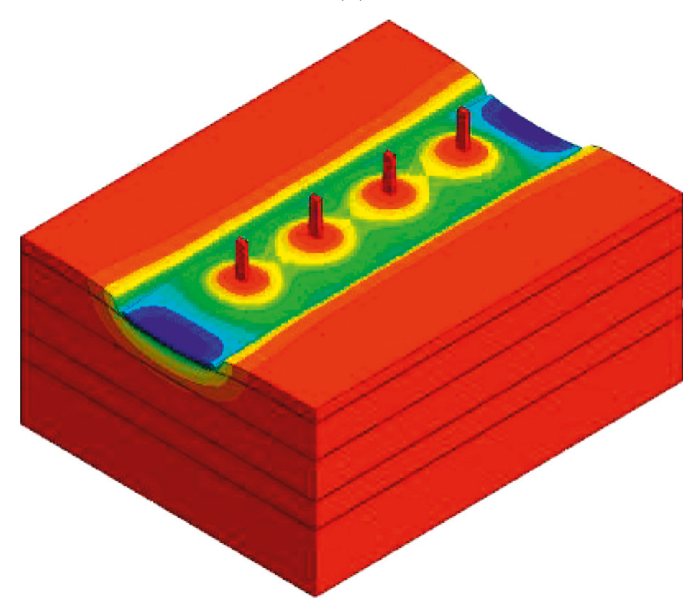

(d)

FIgURE 10: Continued. 


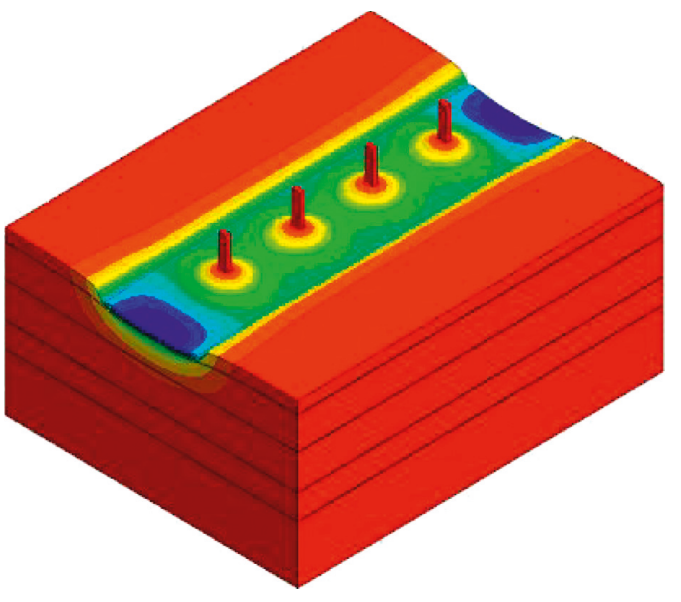

(e)

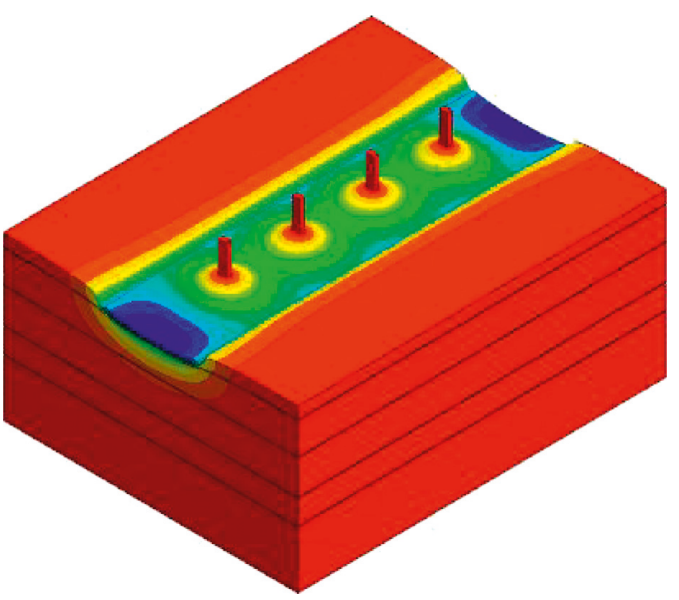

(f)

Figure 10: Overall roadbed settlement for different buried depths of cap. (a) $H=0.2 \mathrm{~m}$. (b) $H=0.85 \mathrm{~m}$. (c) $H=1.35 \mathrm{~m}$. (d) $H=1.85 \mathrm{~m}$. (e) $H=2.35 \mathrm{~m}$. (f) $H=2.85 \mathrm{~m}$.

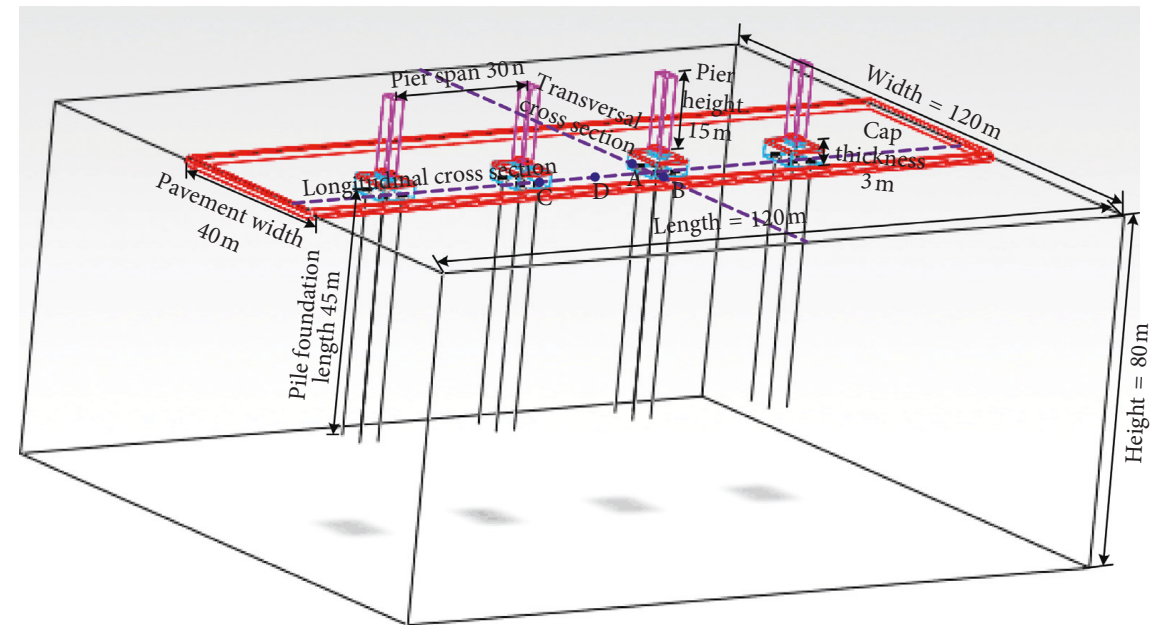

Figure 11: Schematic diagram illustrating the roadbed under viaduct.

TABLE 3: Transverse roadbed settlement for different levels of buried depth of cap $H$.

\begin{tabular}{lccccc}
\hline Buried depth of cap $H(\mathrm{~m})$ & 0.2 & 0.85 & 1.35 & 1.85 & 2.35 \\
Level of settlement at point A (mm) & 8.1 & 8.5 & 9.0 & 10.4 & 24.5 \\
Level of settlement at point B (mm) & 82.3 & 84.2 & 84.6 & 84.0 & 91.5 \\
Settlement fall between point A and B $\Delta s(\mathrm{~mm})$ & 74.2 & 75.7 & 75.6 & 73.6 & 95.7 \\
\hline
\end{tabular}

TABLE 4: Classification of settlement fall.

\begin{tabular}{|c|c|c|c|c|}
\hline Grade of evaluation & Slight & Low & Medium & High \\
\hline Allowed slope varying rate $(\%)$ & $<0.23$ & $0.23-0.37$ & $0.37-0.58$ & $>0.58$ \\
\hline Allowed transverse settlement fall $(\mathrm{mm})$ & $<30$ & $30-50$ & $50-70$ & $>70$ \\
\hline Allowed longitudinal settlement fall (mm) & $<50$ & $50-80$ & $80-120$ & $>120$ \\
\hline
\end{tabular}

buried depth of cap, the more complicated the process is and the higher the construction cost becomes.
4.3. Overall Variation of Roadbed Settlement. The nephograms of the overall settlement of roadbed in Figure 10 demonstrate that 
TABLE 5: Longitudinal roadbed settlement for different buried depths of cap.

\begin{tabular}{|c|c|c|c|c|c|c|}
\hline Buried depth $H(\mathrm{~m})$ & 0.2 & 0.85 & 1.35 & 1.85 & 2.35 & 2.85 \\
\hline Level of settlement at point $C(\mathrm{~mm})$ & 7.4 & 8.4 & 9.8 & 16.9 & 39.5 & 39.3 \\
\hline Level of settlement at point D (mm) & 55.9 & 57.6 & 55.1 & 55.1 & 73.3 & 72.5 \\
\hline Settlement fall between point $\mathrm{C}$ and $\mathrm{D} \Delta s(\mathrm{~mm})$ & 48.5 & 49.2 & 45.3 & 38.2 & 33.8 & 33.2 \\
\hline
\end{tabular}

(1) The smaller is the buried depth of cap, the larger the influence area of the cap is on the surrounding soil mass, i.e., the larger the red area around the cap becomes in the figure.

(2) When the buried depth of cap is " $H=0.2 \mathrm{~m}$ ", the profile of cap can be seen in the postdeformation nephogram, and the roadbed and soil mass are affected in a larger area around the cap.

(3) When the buried depth of cap is " $H=0.85 \mathrm{~m}$ ", the profile of cap cannot be found in the postdeformation nephogram, but the roadbed and soil are affected in a larger area around the cap.

(4) When the buried depths of cap are " $H=1.35 \mathrm{~m}$ ” and " $H=1.85 \mathrm{~m}$ ", the areas have already decreased of the affected roadbed and soil mass around the cap, but the sizes of affected areas are still beyond the size of cap.

(5) When the buried depth of cap is " $H=2.35 \mathrm{~m}$ ", the area of the affected roadbed and soil mass around the cap has shrunk significantly, and the size of the affected area is basically the same as that of the cap.

(6) When the buried depth of cap is " $H=2.85 \mathrm{~m}$ ", the area of the affected roadbed and soil mass around the cap also decreases, but the variation is not significant.

\section{Analysis of the Effect of Relative Stiffness between Pier Cap and Roadbed on the Uneven Settlement of Roadbed}

The stiffness of roadbed refers to the capability of roadbed to resist deformation under the action of external loads. Roadbed is a flexible structure, easy to be compressed and deformed [23]. Bridge and culvert structures are basically reinforced concrete structures with large stiffness, which are difficult to settle and deform. When a viaduct is completed and the road under the viaduct is open to traffic, the compactness of the roadbed and fill at the caps of the viaduct increases, their porosity decreases, and the space between structural layers is compressed. Because the viaduct cap has large stiffness, the resultant settlement deformation of viaduct cap is much smaller than that of the roadbed under the viaduct, so it can be neglected. Over time, when the settlement fall of roadbed relative to the cap exceeds a certain level, settlement or fracture will occur on the asphalt concrete roadbed, and slaggered slab will be formed between them, resulting in differential settlement near the pier cap. In order to facilitate the parameter analysis in this paper, the relative stiffness $R_{p}$ is used to represent the ratio of the stiffness of cap over that of roadbed.

It is generally believed that "stiffness" refers to the capability of a structure or member to resist deformation under load. In engineering, elastic modulus is generally used to measure the stiffness of a structure or member [24]. In order to reduce the relative stiffness between the cap and roadbed, the elastic modulus of roadbed is increased in the simulation analysis. In the model, the buried depth of cap is $2.35 \mathrm{~m}$, and the elastic modulus of roadbed takes $3,000 \mathrm{MPa}, 5,000 \mathrm{MPa}, 10,000 \mathrm{MPa}$, $15,000 \mathrm{MPa}, \quad 20,000 \mathrm{MPa}, 25,000 \mathrm{MPa}$, and $30,000 \mathrm{MPa}$, i.e., " $R_{p}=10.5,6.3,3.15,2.1,1.58,1.26$, and 1.05". The results of simulation are shown in Figures 12-16.

5.1. Transverse Variation of Roadbed Settlement. Figure 12 shows the nephogram of a transverse section of roadbed settlement, in which the positions marked on the road correspond to the two points (A and B) in Figure 11, and the calculated results are listed in Table 6. Both Figure 12 and Table 6 show that the road is relatively convex at the caps and is relatively concave on both sides of the road. As the relative stiffness between the cap and roadbed decreases, the roadbed settlement around the cap does not change much, but the level of settlement on both sides of the road gradually decreases, so the settlement fall between them decreases notably. As the relative stiffness between the cap and roadbed decreases, the transverse settlement fall of roadbed decreases successively.

During the period when the uneven settlement of roadbed is influenced by pier cap, the relative stiffness has a great influence on the transverse settlement falls of roadbed, which are all above $60 \mathrm{~mm}$ and belong to the "medium" grade, as shown in Table 4 . The relationship between the transverse settlement fall of roadbed under urban viaducts and the relative stiffness between the pier caps and roadbed is shown in Figure 13. The relationship between the maximum transverse settlement fall and the relative stiffness between the cap and roadbed can be described by the following function:

$$
\Delta s=-24.15 H^{-1.485}+67.54
$$
that

This function and the plot shown in Figure 13 suggest

(1) When the relative stiffness between cap and roadbed is greater than 6.3 , the decrease of transverse settlement fall is not significant with the decrease of relative stiffness.

(2) When the relative stiffness between cap and roadbed is in the range of 1.58-6.3, the transverse settlement fall decreases smoothly and slowly with the decrease of relative stiffness and the decreasing rate is small. The transverse settlement fall shows a decreasing trend.

(3) When the relative stiffness between cap and roadbed is less than 1.58, the transverse settlement fall 


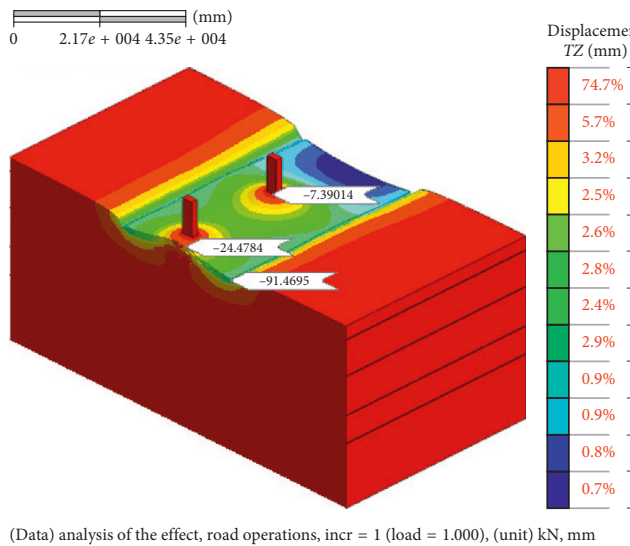

(a)

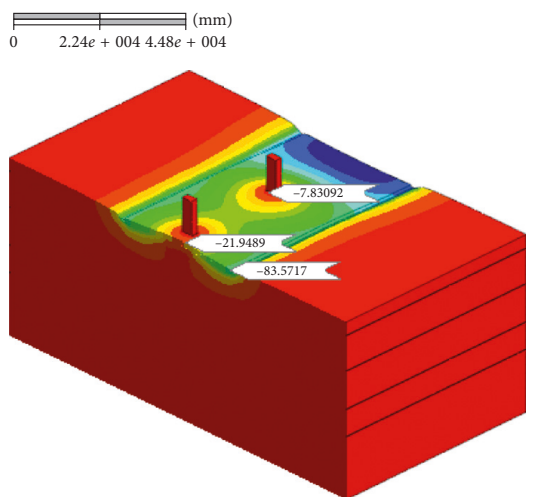

(Data) analysis of the effect, road operations, incr $=1($ load $=1.000)$, (unit) $\mathrm{kN}, \mathrm{mm}$

(c)

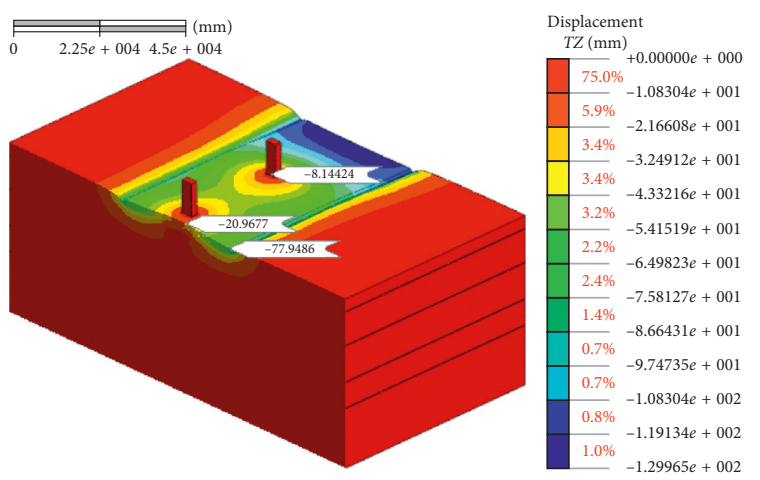

(e)
Displacement
$T Z(\mathrm{~mm})$
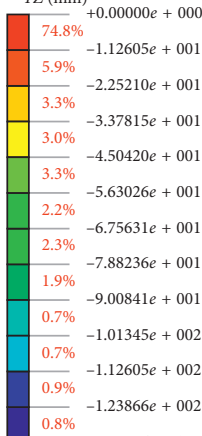

$2.25210 e+001$

$-3.37815 e+00$

$-4.50420 e+001$

$-5.63026 e+00$

$-6.75631 e+00$

$-7.88236 e+00$

$-9.00841 e+001$

$-1.01345 e+002$

$-1.12605 e+002$

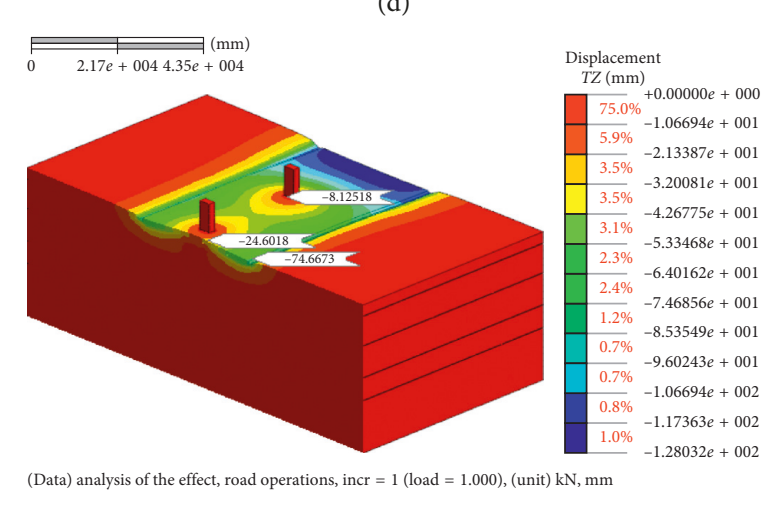

(Data) analysis of the effect, road operations, incr $=1($ load $=1.000)$, (unit) $\mathrm{kN}, \mathrm{mm}$

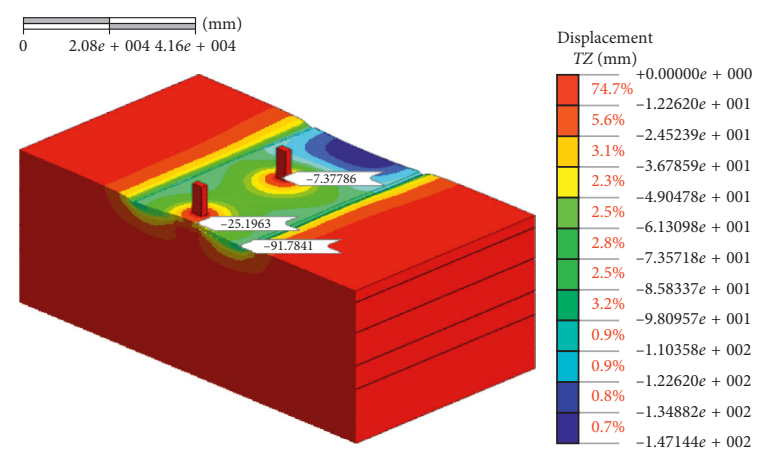

(Data) analysis of the effect, road operations, incr $=1($ load $=1.000)$, (unit) $\mathrm{kN}, \mathrm{mm}$

(b)

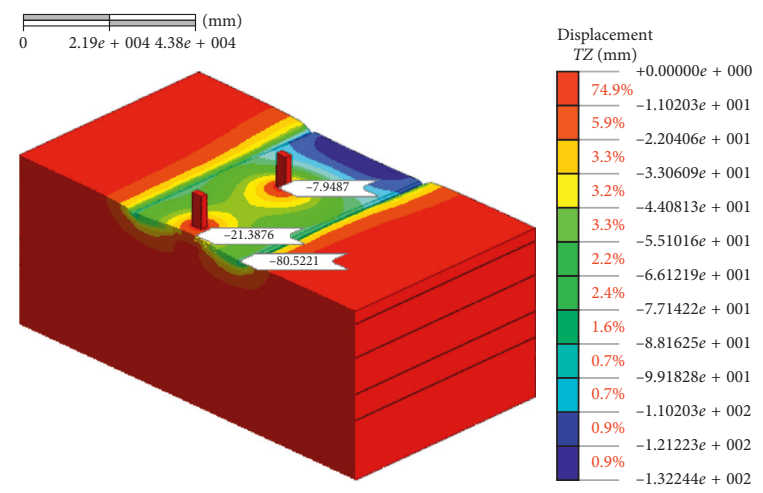

(d)

(f)

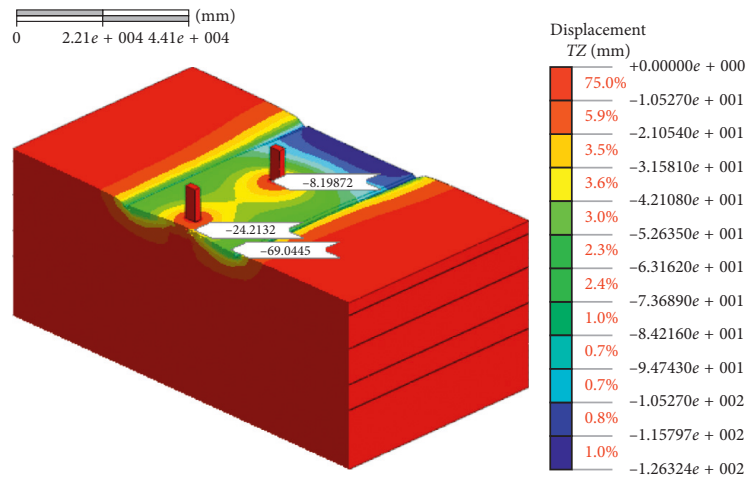

(Data) analysis of the effect, road operations, incr $=1(\mathrm{load}=1.000),(\mathrm{unit}) \mathrm{kN}, \mathrm{mm}$

(g)

FiguRE 12: Transverse section of roadbed settlement for different values of relative stiffness. (a) $R_{p}=10.5$. (b) $R_{p}=6.3$. (c) $R_{p}=3.15$. (d) $R_{p}=2.1$. (e) $R_{p}=1.58$. (f) $R_{p}=1.26$. (g) $R_{p}=1.05$. 


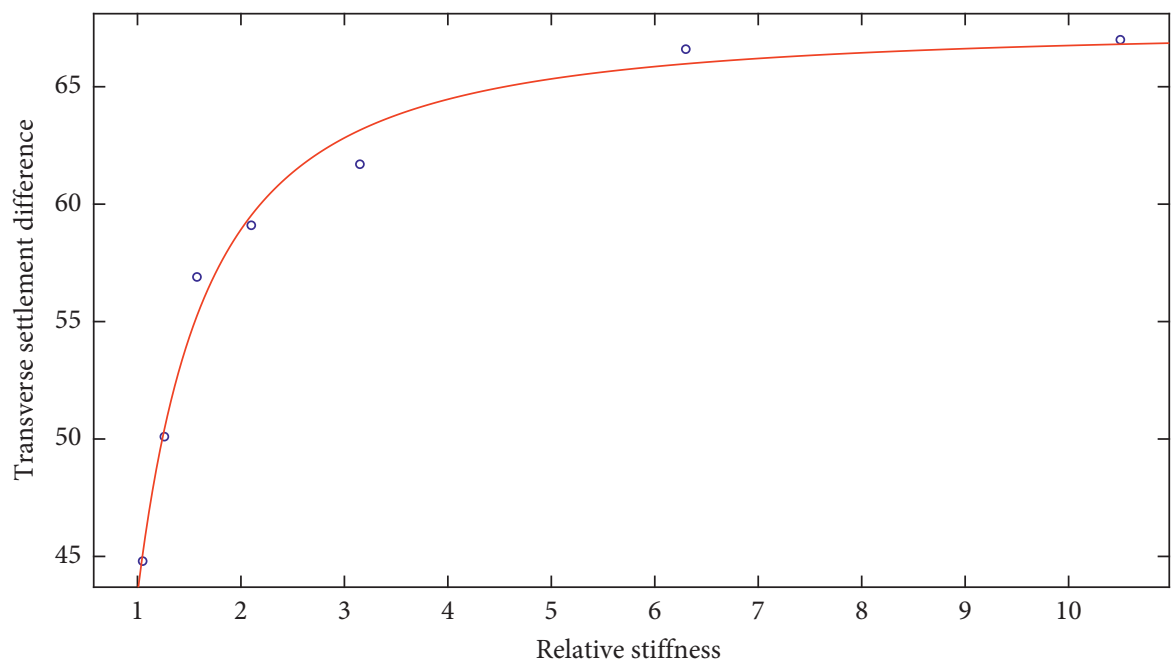

FIGURE 13: The maximum transverse settlement fall of the roadbed under viaduct versus the relative stiffness of cap.

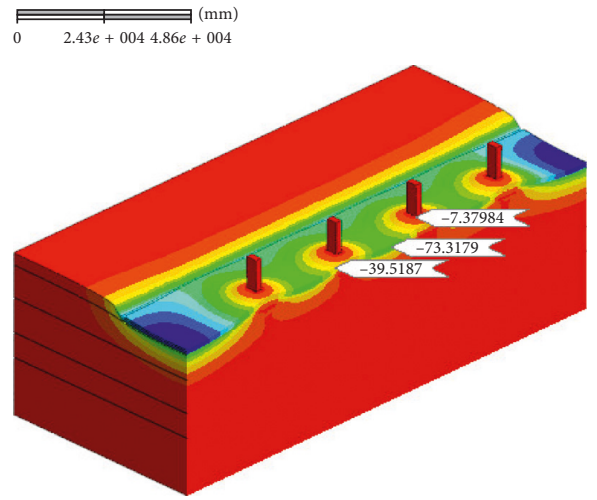

(Data) analysis of the effect, road operations, incr $=1($ load $=1.000)$, (unit) $\mathrm{kN}, \mathrm{mm}$

(a)

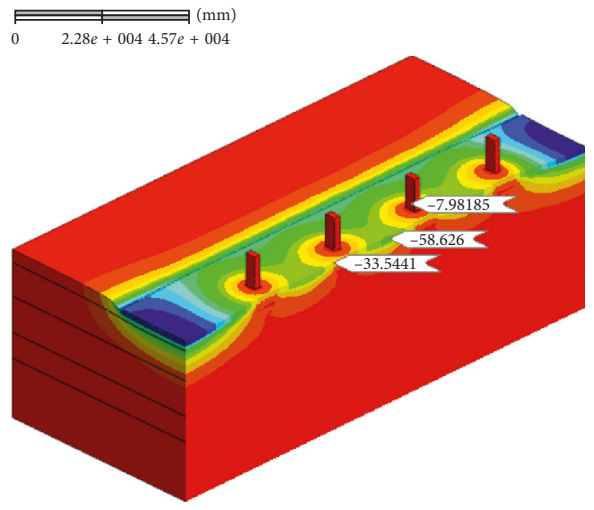

(Data) analysis of the effect, road operations, incr $=1($ load $=1.000)$, (unit) $\mathrm{kN}, \mathrm{mm}$

(c)

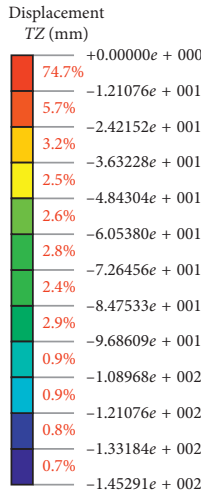

$-1.45291 e+002$

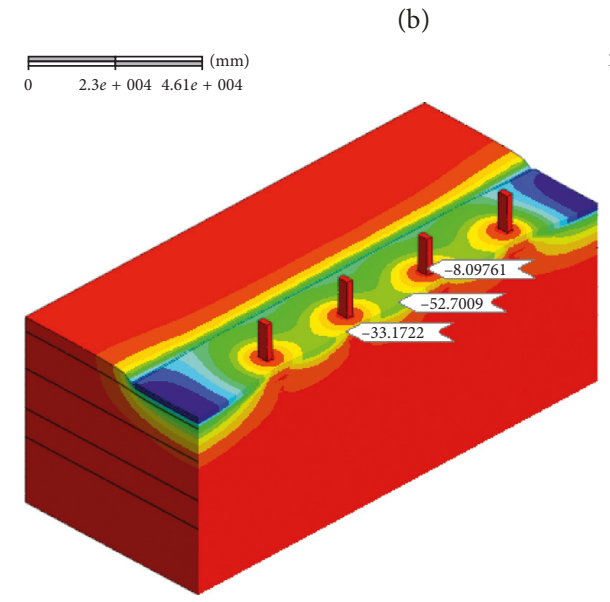

(Data) analysis of the effect, road operations, incr $=1($ load $=1.000),($ unit $) \mathrm{kN}, \mathrm{mm}$

(d)

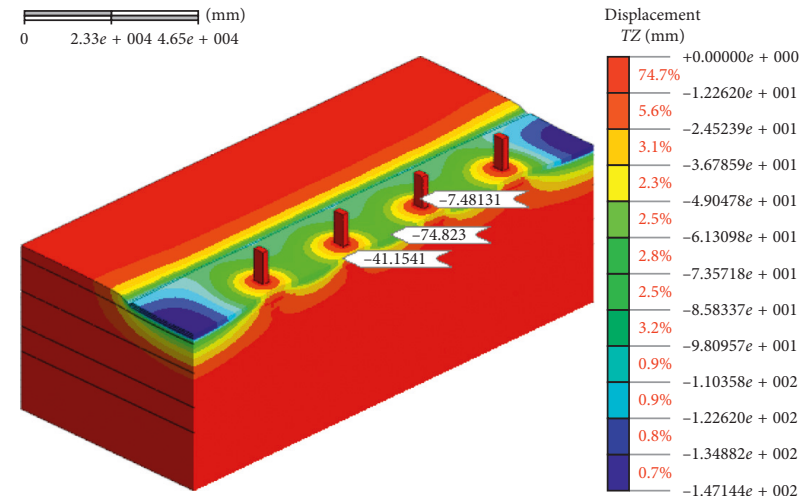

$-1.47144 e+002$

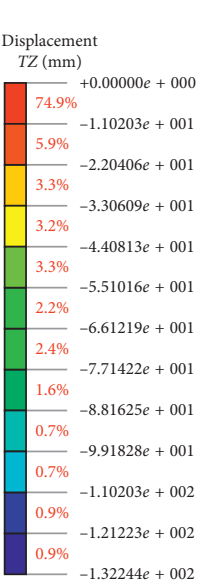

$-1.32244 e+002$

FIgURe 14: Continued. 


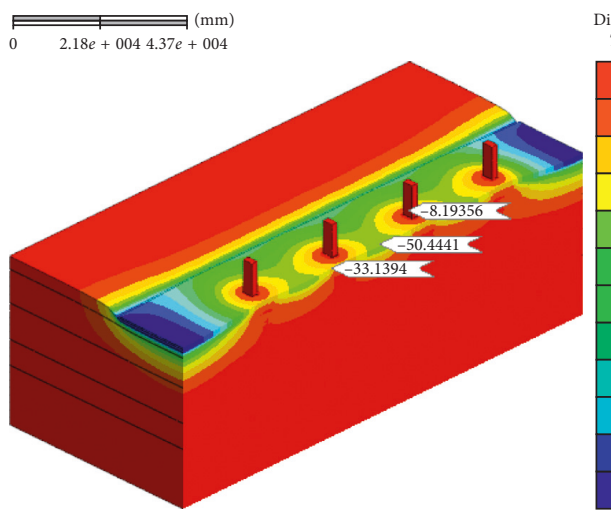

(e)

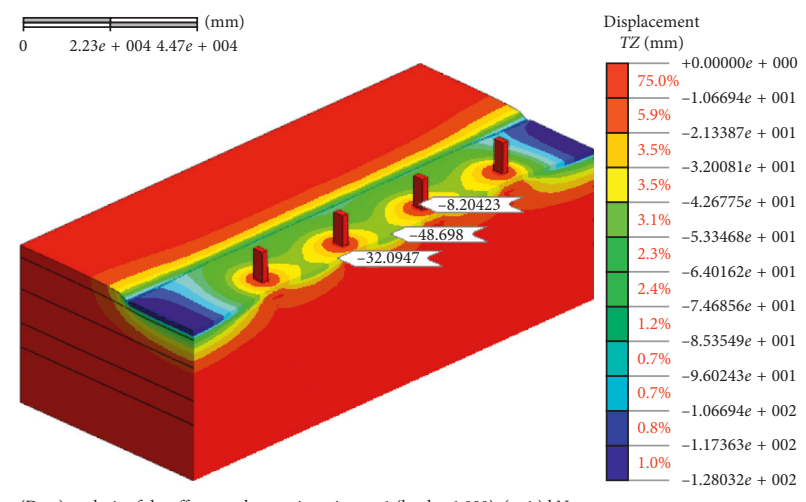

(f)

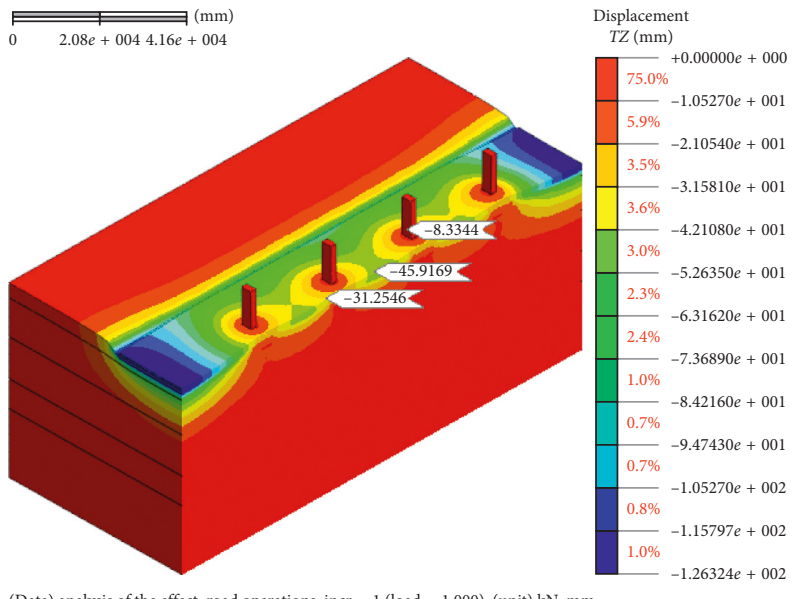

(Data) analysis of the effect, road operations, incr $=1($ load $=1.000)$, (unit) $\mathrm{kN}, \mathrm{mm}$

(g)

FIGURE 14: Longitudinal section of roadbed settlement for different values of relative stiffness. (a) $R_{p}=10.5$. (b) $R_{p}=6.3$. (c) $R_{p}=3.15$. (d) $R_{p}=2.1$. (e) $R_{p}=1.58$. (f) $R_{p}=1.26$. (g) $R_{p}=1.05$.

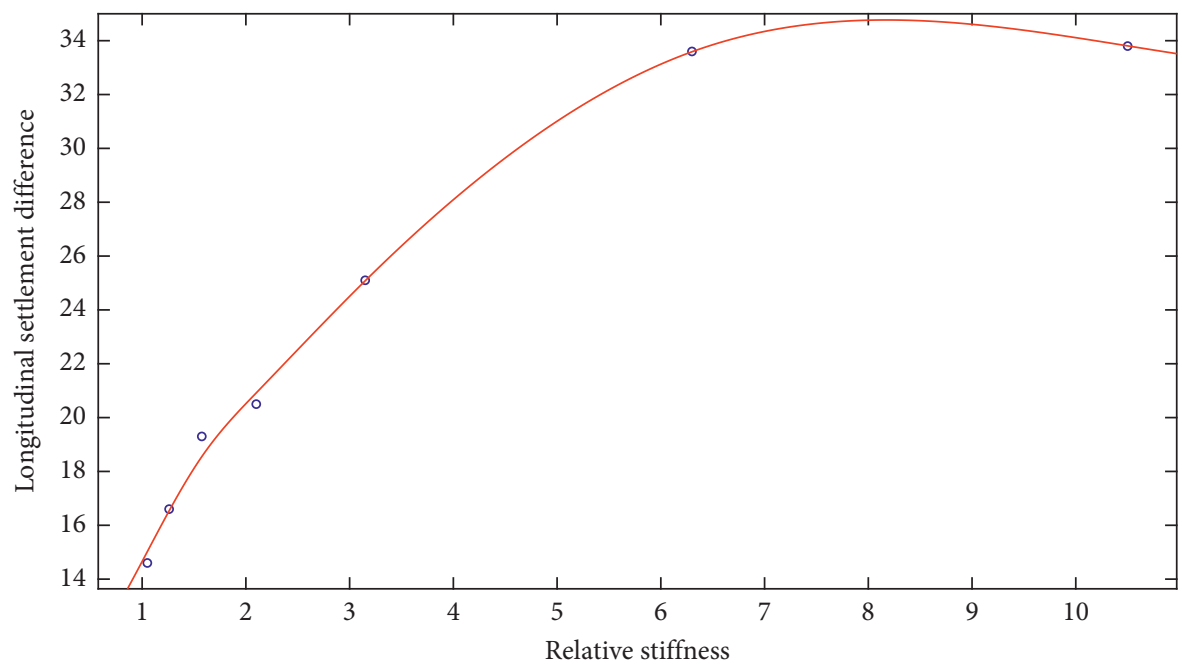

FIGURE 15: The relationship between longitudinal settlement fall and relative stiffness.

significantly decreases with the decrease of relative stiffness. The rate of decline is larger, and the amount of fall reduction is also greater.
In addition, in order to ensure the performance of the highways under urban viaducts, the design specification relevant to Table 4 requires that the maximum transverse 


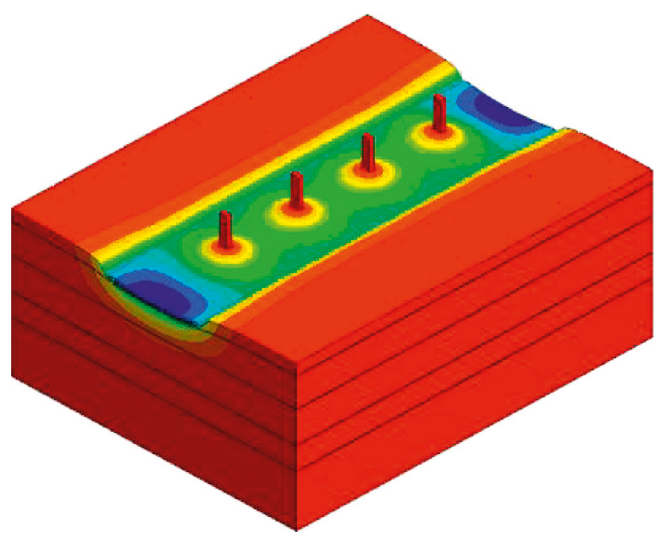

(a)

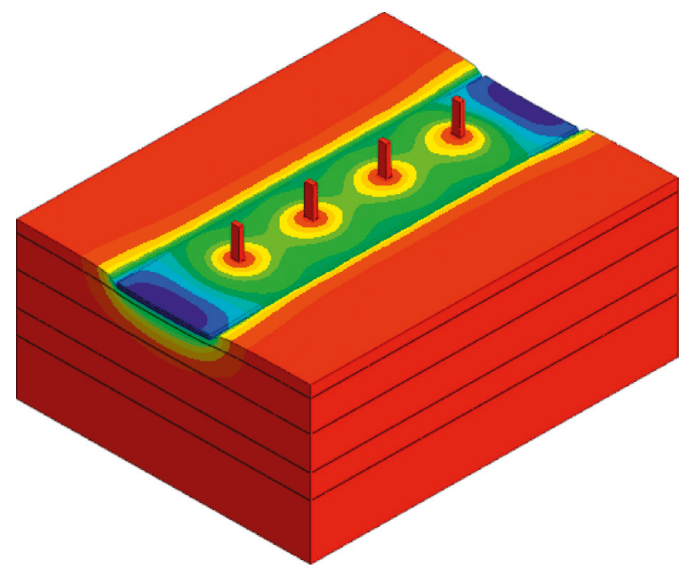

(c)

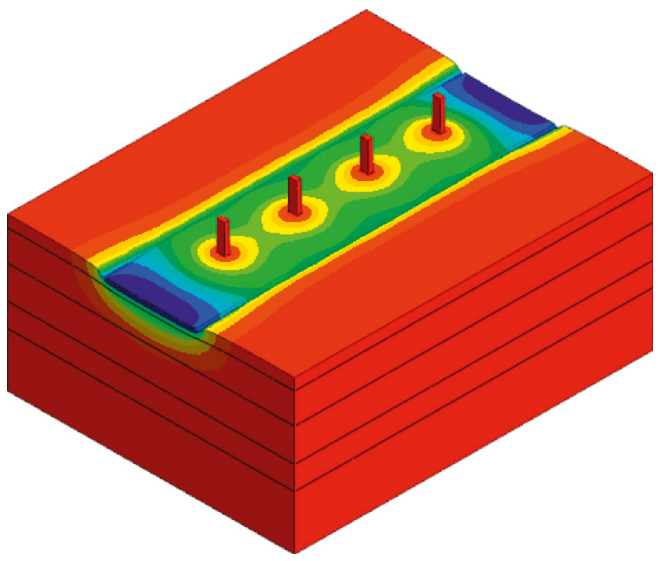

(e)

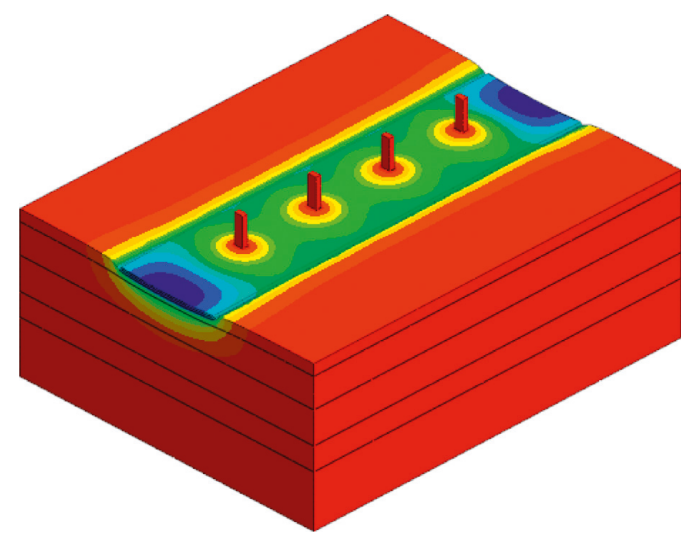

(b)

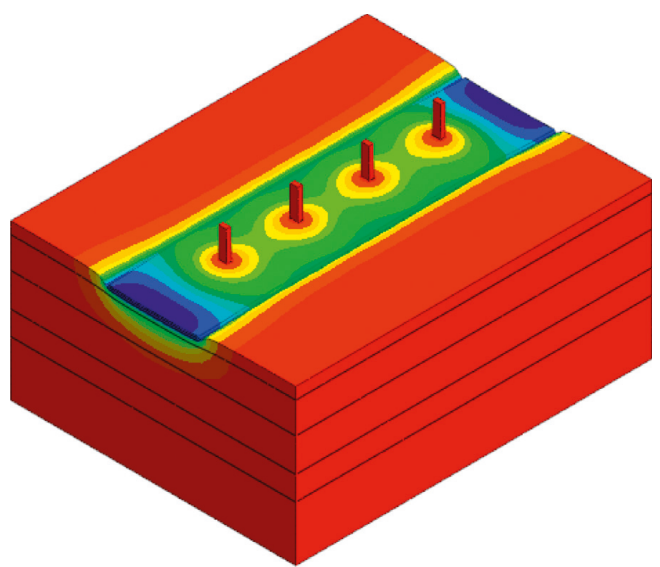

(d)

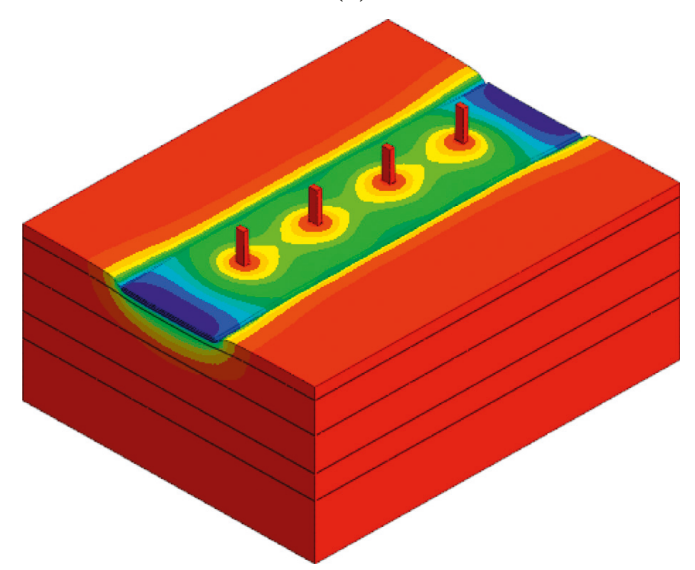

(f)

Figure 16: Continued. 


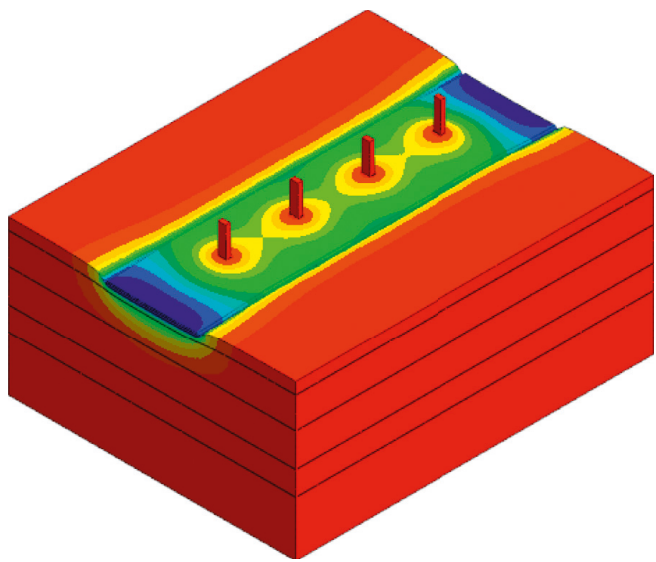

(g)

FiguRe 16: Overall roadbed settlement for different values of relative stiffness. (a) $R_{p}=10.5$. (b) $R_{p}=6.3$. (c) $R_{p}=3.15$. (d) $R_{p}=2.1$. (e) $R_{p}=1.58$. (f) $R_{p}=1.26$. (g) $R_{p}=1.05$.

TABLE 6: Transverse roadbed settlement for different values of relative stiffness.

\begin{tabular}{|c|c|c|c|c|c|c|c|}
\hline Relative stiffness & 10.5 & 6.3 & 3.15 & 2.1 & 1.58 & 1.26 & 1.05 \\
\hline Level of settlement at point $A(\mathrm{~mm})$ & 24.5 & 25.2 & 21.9 & 21.4 & 21.0 & 24.6 & 24.2 \\
\hline Level of settlement at point B (mm) & 91.5 & 91.8 & 83.6 & 80.5 & 77.9 & 74.7 & 69.0 \\
\hline Settlement fall between point $\mathrm{A}$ and B $\Delta s(\mathrm{~mm})$ & 67.0 & 66.6 & 61.7 & 59.1 & 56.9 & 50.1 & 44.8 \\
\hline
\end{tabular}

settlement fall of roadbed shall not be more than $60 \mathrm{~mm}$. According to the above calculations, the relative stiffness of cap should not be greater than $2.19 \mathrm{~m}$. Therefore, measures should be taken to ensure that when a highway lies under an urban viaduct, the relative stiffness of viaduct cap should be within the range of $1.58-2.19$, which is good for the control of maximum transverse settlement fall of the roadbed under the viaduct and ensure the service performance of the road under the viaduct.

\subsection{Longitudinal Variation of Roadbed Settlement.} Figure 14 shows the nephograms of a longitudinal section of roadbed settlement, in which the positions marked on the road correspond to the $\mathrm{C}$ and $\mathrm{D}$ points in Figure 11, and the calculated results are listed in Table 7 . According to the trend of variation indicated in Figure 14 and Table 7, with the decrease of relative stiffness between cap and roadbed, the amplitude of the "wave shape" variation of roadbed is weakened, i.e., the settlement fall of roadbed gradually decreases and the overall level of settlement is also reduced; with the decrease of relative stiffness between cap and roadbed, the longitudinal settlement fall decreases gradually, and the longitudinal fall is smaller than the transverse settlement fall.

During the period when the uneven settlement of roadbed is affected by the pier caps, the relative stiffness has little effect on the longitudinal settlement falls of roadbed, which are not more than $50 \mathrm{~mm}$ and belong to the "low" grade according to Table 4 . Figure 15 shows the following relationship between the longitudinal settlement fall and the relative stiffness between pier cap and roadbed:
(1) When the relative stiffness between cap and roadbed is greater than 6.3, the decrease of longitudinal settlement fall is not significant with the decrease of relative stiffness.

(2) When the relative stiffness between cap and roadbed is in the range of $2.1 \sim 6 \mathrm{~m}$, with the decrease of relative stiffness, the longitudinal settlement fall successively decreases significantly. The rate of decline is larger, and the extent of fall reduction is also larger.

(3) When the relative stiffness between cap and roadbed is less than $2.1 \mathrm{~m}$, with the decrease of relative stiffness, the longitudinal settlement fall still decreases successively. The variation is more significant, the rate of decline is larger than before, and the extent of fall reduction also continues to get larger.

5.3. Overall Variation of Roadbed Settlement. The simulated results of the overall vertical settlement of the roadbed are shown in the nephograms in Figure 16, which indicate that

(1) As the relative stiffness between cap and roadbed decreases, the range of the decreased settlement of roadbed gradually increases, i.e., the yellow area around the cap gets wider.

(2) When the relative stiffness between cap and roadbed is 10.5 and 6.3, there is little difference between the two maps of overall vertical settlement.

(3) When the relative stiffness between cap and roadbed is less than 3.15, the yellow area is significantly 
TABLE 7: Longitudinal roadbed settlement for different values of relative stiffness.

\begin{tabular}{|c|c|c|c|c|c|c|c|}
\hline Relative stiffness & 10.5 & 6.3 & 3.15 & 2.1 & 1.58 & 1.26 & 1.05 \\
\hline Level of settlement at point $C(\mathrm{~mm})$ & 39.5 & 41.2 & 33.5 & 32.2 & 31.1 & 32.1 & 31.3 \\
\hline Level of settlement at point $\mathrm{D}(\mathrm{mm})$ & 73.3 & 74.8 & 58.6 & 52.7 & 50.4 & 48.7 & 45.9 \\
\hline Settlement fall between point $\mathrm{C}$ and $\mathrm{D} \Delta s(\mathrm{~mm})$ & 33.8 & 33.6 & 25.1 & 20.5 & 19.3 & 16.6 & 14.6 \\
\hline
\end{tabular}

enlarged in the map of overall vertical settlement, i.e., the overall settlement of roadbed is gradually decreasing. This result also suggests that improving the elastic modulus of the roadbed can reduce the settlement of roadbed.

\section{Conclusions and Future Work}

In this paper, roadbed settlement under the viaduct of the Wuhan Huangpu Street-Jinqiao Avenue Expressway is taken as the research background, and based on the results of field investigation, two influential factors are proposed: the buried depth of cap and the relative stiffness between cap and subgrade soil. Then, through modeling and simulation analysis with the Midas GTS NX software, the influence of the settlement of the cap foundation of urban viaduct is studied on the uneven settlement of the roadbed under the viaduct. This study may provide some reference for the maintenance of road works under urban viaducts, and the following conclusions are drawn:

(1) When the buried depth of cap is less than $0.85 \mathrm{~m}$, with the increase of buried depth, the settlement fall of roadbed decreases gradually, but the extent of decreasing is not significant. When the buried depth of cap is in the range of $0.85-2.35 \mathrm{~m}$, with the continuous increase of buried depth, the settlement fall of roadbed decreases gradually, and the extent of reduction gets larger. When the buried depth of cap exceeds $2.35 \mathrm{~m}$, with the increase of buried depth, the settlement fall decreases gradually, but the extent of reduction is not significant. In addition, according to the stipulation that the transverse settlement fall of roadbed caused by the buried depth of cap shall not exceed $70 \mathrm{~mm}$, the corresponding buried depth of cap should be less than $2.28 \mathrm{~m}$. In consideration of saving construction costs, the buried depth of cap pile should be controlled within the range of $0.85-$ $2.28 \mathrm{~m}$, depending on the engineering conditions.

(2) The settlement fall of roadbed decreases with the decrease of the relative stiffness between cap and roadbed. When the relative stiffness exceeds 6.3 , the descending variation of settlement fall is not significant. When the relative stiffness between cap and roadbed is in the range of 2.1-6.3, with the decrease of relative stiffness, the longitudinal settlement fall of roadbed decreases significantly, the rate of descending is larger and the extent of reduction is also larger. When the relative stiffness between cap and roadbed is less than 2.1, with the decrease of relative stiffness, the longitudinal settlement fall still decreases significantly, the rate of decline is still larger, and the extent of reduction is also larger. In addition, according to the stipulation that the transverse fall of roadbed settlement caused by the relative stiffness between cap and roadbed shall not exceed $60 \mathrm{~mm}$, the corresponding relative stiffness should be less than 2.19. In consideration of saving construction costs, the relative stiffness of the cap piles of viaduct should be within the range of $1.58-2.19$, depending on the general situation of the project. It is recommended that rigid concrete roadbed be used for alleviating the differential settlement of roadbed.

(3) In this paper, the influence of the pier caps of urban viaducts on the uneven settlement of roadbed is analyzed and studied. Through field investigation, the related principles and relevant theories are reviewed. A numerical analysis model of the deformation of roadbed under viaduct is constructed to study the influence of cap foundation on the uneven settlement of roadbed under viaduct. Although some relatively effective results are obtained in this paper, more in-depth discussion and research are still required. In the simulation in this paper, the homogeneity of each layer of soil is assumed, which is inconsistent with the actual geological conditions. In the next step, we hope to improve the finite element model to simulating more realistic situations for the purpose of achieving more effective results on the effect of the cap foundation of viaduct on the uneven settlement of roadbed under viaduct.

In future work, we will include more existing problems found in more practical projects into the scope of investigation and apply more technical means, such as field test or numerical calculation, to study the mechanism of uneven settlement of roadbed under viaduct. The results will also be applied to the construction process, and eventually effective methods will be established to solve related problems.

\section{Data Availability}

The data used to support the findings of this study are included within the article. The calculation model used to support the findings of this study is available from the corresponding author upon request.

\section{Conflicts of Interest}

The authors declare that there are no conflicts of interest regarding the publication of this paper. 


\section{Acknowledgments}

The project was financed by the Wuhan Urban and Rural Construction Committee (Grant no. 2015-44). The authors thank the workers, foremen, and safety coordinators of the main contractors for their participation.

\section{References}

[1] T. Zhao, W. Liu, and Z. Ye, "Effects of water inrush from tunnel excavation face on the deformation and mechanical performance of shield tunnel segment joints," Advances in Civil Engineering, vol. 2017, Article ID 5913640, 18 pages, 2017.

[2] W. Liu, T. Zhao, W. Zhou, and J. Tang, "Safety risk factors of metro tunnel construction in China: an integrated study with EFA and SEM," Safety Science, vol. 105, pp. 98-113, 2018.

[3] K. Terzaghi, Theoretical Soil Mechanics, Chapman \& Hall, London, UK, 1943.

[4] F. Zhou, Z. Chen, and X. D. Wang, "An equal-strain analytical solution for the radial consolidation of unsaturated soils by vertical drains considering drain resistance," Advances in Civil Engineering, vol. 2018, Article ID 5069159, 9 pages, 2018.

[5] M. A. Biot, "General theory of three-dimensional consolidation," Journal of Applied Physics, vol. 12, no. 2, pp. 155-164, 1941.

[6] Y.-Y.Hu, W.-H. Zhou, and Y.-Q. Cai, "Reply to the discussion by Mesri and Wang on "Large-strain elastic viscoplastic consolidation analysis of very soft clay layers with vertical drains under preloading"," Canadian Geotechnical Journal, vol. 52, no. 1, pp. 127-128, 2015.

[7] M. Mikasa, The Consolidation of Soft Clay: A New Consolidation Theory and Its Application, Japanese Society Civil Engineers, JSCE, Tokyo, Japan, 1965.

[8] D. Li and C. Yan, "Building deformation prediction based on ground surface settlements of metro-station deep excavation," Advances in Civil Engineering, vol. 2018, Article ID 6050353, 14 pages, 2018.

[9] L. Jia, J. Guo, and K. Yao, "In situ monitoring of the long-term settlement of high-fill subgrade," Advances in Civil Engineering, vol. 2018, Article ID 1347547, 9 pages, 2018.

[10] X. Ling, L. Peng, F. Zhang, Y. Zhao, Y. Li, and L. An, "Permanent deformation characteristics of coarse grained subgrade soils under train-induced repeated load," Advances in Materials Science and Engineering, vol. 2017, Article ID 6241479, 15 pages, 2017.

[11] H. L. Zhao, Z. J. Hui, and J. Lin, "Study on soft foundation settlement analysis and treatment of bridge-head," Advanced Materials Research, vol. 779-780, pp. 632-635, 2013.

[12] C. L. Snow and C. R. Nickerson, "Case study of EPS geofoam lightweight fill for settlement control at bridge approach embankment," in Proceedings of the Geotechnical Engineering for Transportation Projects, pp. 580-589, Los Angeles, CA, USA, July 2004.

[13] C. R. Byrum, K. C. McDevitt, and S. J. Magnan, "Instrumented geofoam and sheet pile wall for a roadway lane addition in a peat marsh," in Proceedings of the Geotechnical Engineering for Transportation Projects, pp. 600-608, Los Angeles, CA, USA, July 2004.

[14] Y. Changwei, T. Xinhao, Z. Jianjing, and Z. Haobo, "A new design of bridge-subgrade transition sections applied in Beijing-Shanghai high-speed railway," Complexity, vol. 2018, Article ID 1249092, 11 pages, 2018.
[15] E. B. Pancar and M. V. Akpinar, "Comparison of effects of using geosynthetics and lime stabilization to increase bearing capacity of unpaved road subgrade," Advances in Materials Science and Engineering, vol. 2016, Article ID 7129356, 8 pages, 2016.

[16] J. Zhang, S.-W. Liu, and H.-F. Pu, "Evaluation of an improved technique for geosynthetic-reinforced and pile-supported embankment," Advances in Materials Science and Engineering, vol. 2015, Article ID 612760, 9 pages, 2015.

[17] P. K. Kolay, S. Kumar, and D. Tiwari, "Improvement of bearing capacity of shallow foundation on geogrid reinforced silty clay and sand," Journal of Construction Engineering, vol. 2013, Article ID 293809, 10 pages, 2013.

[18] W. Zhang, D. Du, and X. Bai, "In situ testing of square footing resting on geobelt-reinforced gravel thin cushion on soft silt," Advances in Materials Science and Engineering, vol. 2018, Article ID 3563914, 12 pages, 2018.

[19] J. Jaymohan and R. Shivashankar, "Some studies on prestressed reinforced granular beds overlying weak soil," ISRN Civil Engineering, vol. 2012, Article ID 436327, 13 pages, 2012.

[20] Y. Zhang, Mountain highway subgrade differential settlement characteristics and control measures, Ph.D. dissertation, Chang'an University, Xi'an, China, 2009, in Chinese.

[21] Ministry of Communications and Communications of the People's Republic of China, Specifications for Highway Subgrade Design, People's Communications Publishing House Limited, Beijing, China, 2015, in Chinese.

[22] Ministry of Housing and Urban Rural Development of People's Republic of China, Code for Design of Urban Road Subgrade, China Construction Industry Press, Beijing, China, 2013, in Chinese.

[23] Z. J. Ye, Y. Lu, and L. B. Wang, "Investigating the pavement vibration response for roadway service condition evaluation," Advances in Civil Engineering, vol. 2018, Article ID 2714657, 14 pages, 2018.

[24] N. Consoli, R. A. Samaniego, L. E. González, E. J. Bittar, and O. Cuisinier, "Impact of severe climate conditions on loss of mass, strength, and stiffness of compacted fine-grained soils-portland cement blends," Journal of Materials in Civil Engineering, vol. 30, no. 8, article 04018174, 2018. 


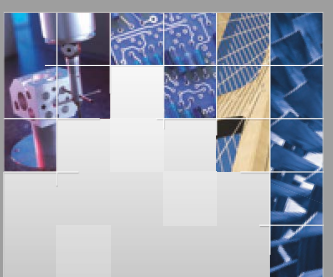

\section{Enfincering}
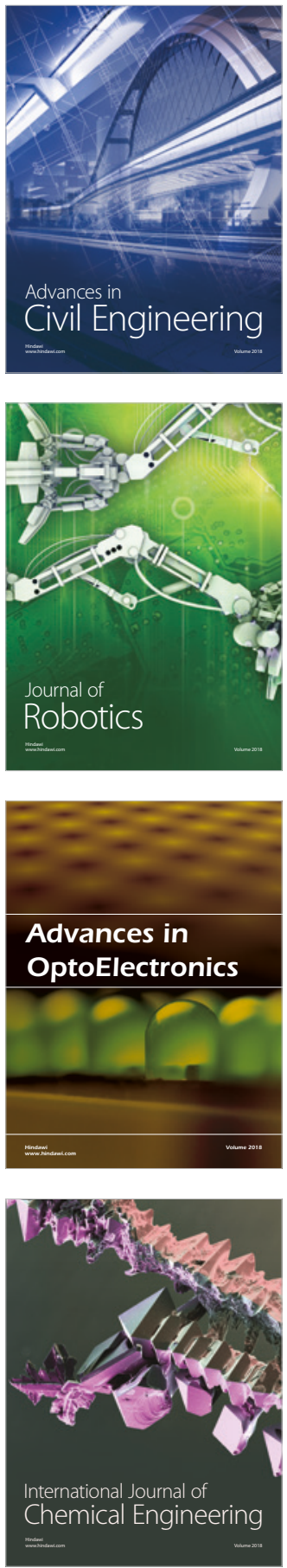

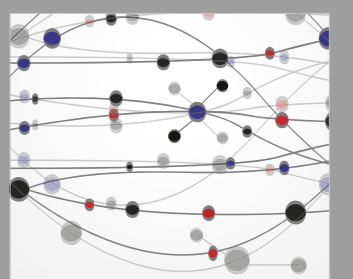

\section{Rotating \\ Machinery}

The Scientific World Journal

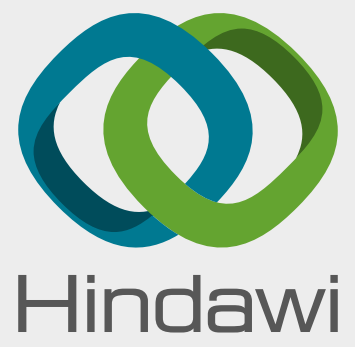

Submit your manuscripts at

www.hindawi.com
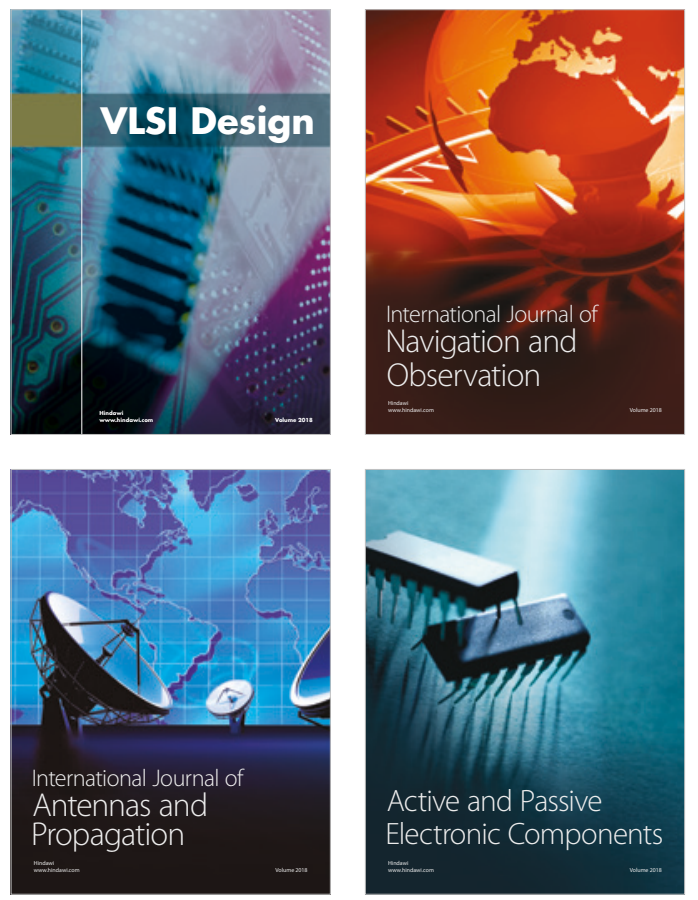
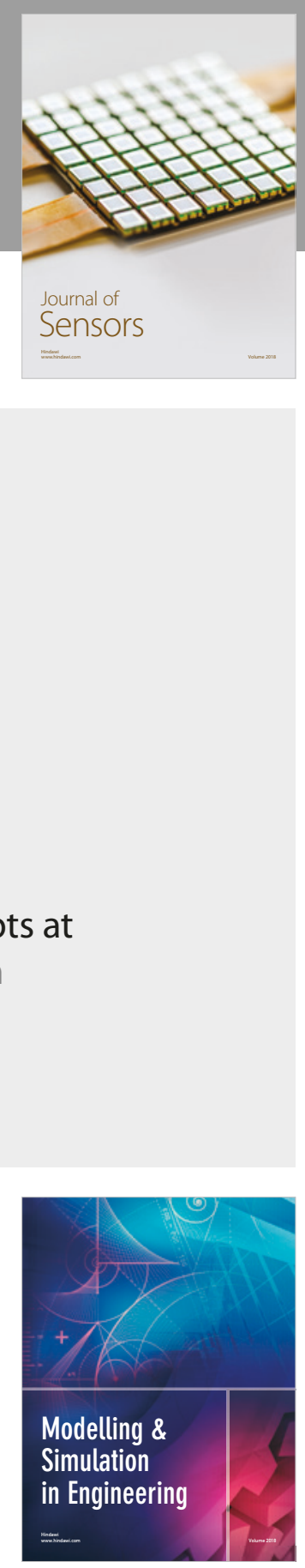

\section{Advances \\ Multimedia}
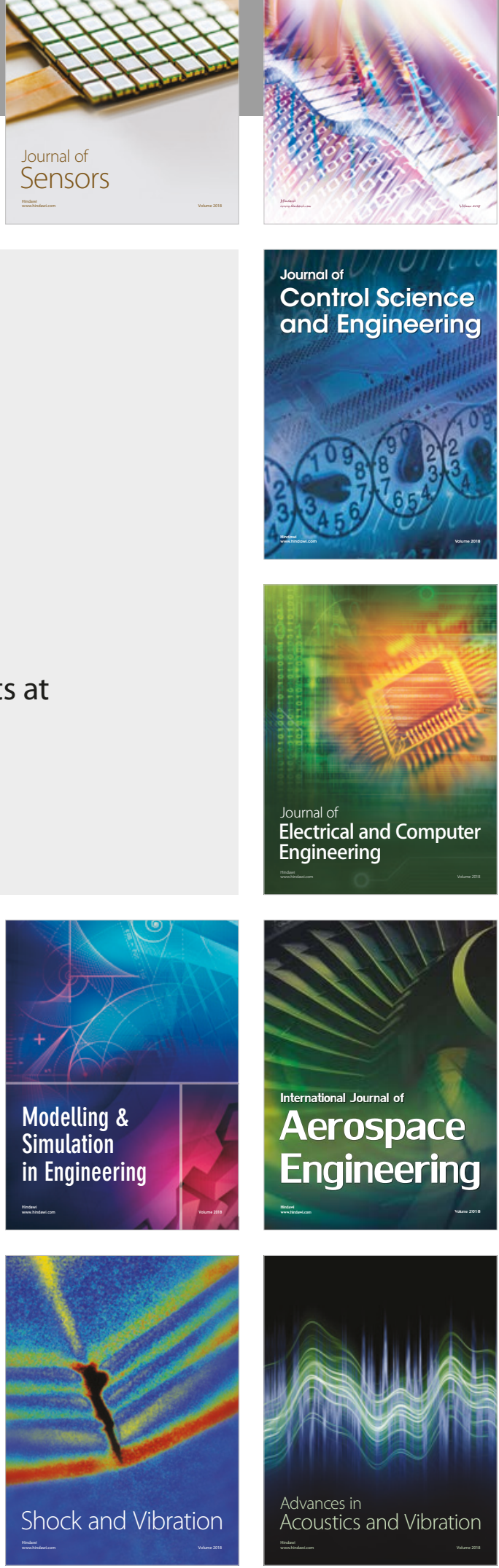